\title{
Accommodating Log Dimensions and Geometry in Log Procurement Decisions for Spindleless Rotary Veneer Production
}

\author{
Tyron J. Venn, ${ }^{\mathrm{a}, *}$ Robert L. McGavin, ${ }^{\mathrm{b}}$ and Alisher Ergashev ${ }^{\mathrm{c}}$ \\ Information to support efficient log procurement decisions based on log \\ cost as well as volume and value of veneer produced from log volume is \\ scarce. The objective of this study was to systematically investigate the \\ effect of log dimensions and geometry (small-end diameter under bark \\ (SEDUB), taper, sweep, and ovality) on the recovery of marketable veneer \\ from log volume, and to produce a metric to support efficient log \\ procurement decisions. The metric developed was the maximum that \\ could be paid for mill-delivered logs of a specific log geometry (MDLC $C_{\text {max }}$ ) \\ while attaining a target gross margin. In decreasing order of impact on the \\ net recovery of marketable veneer from log volume, the log characteristics \\ were sweep, SEDUB, taper, and ovality. In an Australian case study, log \\ dimensions and geometry were found to substantially affect MDLC $C_{\max }$. \\ Relative to a $2.6-\mathrm{m}$ cylindrical log, taper of $0.01 \mathrm{~m} / \mathrm{m}$ of log length \\ decreased $M D L C \max \$ 10 / \mathrm{m}^{3}$ and sweep of $0.01 \mathrm{~m} / \mathrm{m}$ of log length \\ decreased $M D L C_{\max } \$ 20 / \mathrm{m}^{3}$. This metric is useful for supporting log \\ procurement decisions of the timber industry.
}

Keywords: Engineered wood products; Taper; Sweep; Ovality; Small-end diameter under bark;

Veneer recovery; Gross margin

Contact information: a: School of Agriculture and Food Sciences, The University of Queensland, St. Lucia, Queensland, 4072, Australia; b: Agri-Science Queensland, Queensland Department of Agriculture and Fisheries, Salisbury, Queensland, 4107, Australia; c: Strategic Policy and Planning, Queensland

Department of Agriculture and Fisheries, Brisbane, Queensland, 4000, Australia;

* Corresponding author: t.venn1@uq.edu.au

\section{INTRODUCTION}

Many countries are increasingly reliant on shorter rotation timber plantations or have large volumes of low-grade plantation or native forest logs that are destined for lowvalue products such as landscaping, woodchips, and bioenergy (Leggate et al. 2017). For example, in Australia, processing studies milling the traditional suite of sawnwood products from plantation eucalypt logs have typically yielded less than half of the product recovery achieved with eucalypt logs from mature native forests (Leggate et al. 2000; Washusen et al. 2009; Blakemore et al. 2010a,b; Washusen 2011; Washusen and Harwood 2011; McGavin and Leggate 2019). This represents a poor return on investment for forest growers and sawmillers. Although advances have been made in small log sawmilling, low volume recoveries remain and defects limit sawnwood grade quality. Rotary veneer processing enables a much higher volume recovery from small logs, and the manufacture of veneer-based products allows for randomisation of defects, such that defects are not concentrated at one location in the product and attainment of a marketable grade is possible (Leggate et al. 2017). A traditional spindle rotary veneer lathe allows recovery of veneer down to a residual cylindrical peeler core diameter of usually greater than $0.15 \mathrm{~m}$. In

Venn et al. (2020). "Log geometry for log procurement," BioResources 15(2), 2385-2411. 2385 
contrast, a spindleless rotary veneer lathe can recover veneer down to a residual core diameter of less than $0.05 \mathrm{~m}$. The proliferation of spindleless rotary veneer processing plants, particularly in Asia, suggests that a higher return on investment can be achieved if small log resources are processed into veneer-based engineered wood products (Arnold $e t$ al. 2013; Leggate et al. 2017).

Knowledge of mechanical properties of veneer-based engineered wood products from small diameter trees is increasingly available for North American softwood species (Sorenson 1985; Spelter and Sleet 1989; Pease 1993; Dobner, Jr. et al. 2013; Wang and Dai 2013), temperate and subtropical eucalypt species (McGavin et al. 2014a,b, 2015a,b; Gilbert et al. 2017), and other species such as Asian rubber trees (Khoo et al. 2018) and European birch (Verkasalo 1997; Heräjärvi and Arponen 2008; Verkasalo and Heräjärvi 2009). All these studies have reported favourable veneer recovery rates and mechanical properties from small logs. Engineered wood products manufactured from veneers recovered from young hardwood plantation logs can exceed the mechanical properties of similar products manufactured from mature-age softwood (e.g., Pinus species) plantation logs (Gaunt et al. 2003; De Carvalho et al. 2004; Rahayu et al. 2015).

The value of logs at the lathe for production of veneer-based engineered wood products is determined by green veneer recovery and utility after drying the green veneer (Fahey and Willtts 1991). Green veneer recovery from log volume is affected by the residual cylindrical peeler core diameter, as well as log dimensions and geometry. Log-end splitting and wood decay affect how closely the machine design residual core diameter (CD) can be reached (Hamilton et al. 2015). Small-end diameter under bark (SEDUB), taper (T), sweep (S), and ovality (O) (out-of-roundness) will affect the proportion of log volume lost when logs are rounded to a cylindrical peeler billet prior to rotary peeling (Luo et al. 2013; McGavin et al. 2014a,b). As log diameter decreases, the relative impact of log geometry on green veneer recovery increases. Thus, there has been a research focus on identifying which log traits most affect green veneer recovery from log volume (Luo et al. 2013; Peng et al. 2014; Hamilton et al. 2015). However, no consensus has arisen from this research, in part because analysis approaches have not separated log dimensions and geometry influences from the grade quality of wood recovered as a result of the deconstruction process.

Table 1 summarises net recovery (NR) of marketable veneer as a percentage of mill-delivered log volume (MDLV), and the proportion of marketable veneer recovered by veneer grade, from splindleless lathe research trials in Australia. The reported mean NRs combine the effects of waste due to log dimensions and geometry, internal defects (from imperfections inside the log), clipping, shrinkage during drying, grading, and trimming to final product dimensions. An estimate of marketable veneer recovery from peelable log volume (MVRPLV) is necessary to isolate the effect of log dimensions and geometry from other factors on the recovery of marketable veneer from log volume.

Veneer manufacturers need a simple metric to assess how log dimensions and geometry affect marketable veneer recovery and value so that efficient log procurement decisions can be made. Amishev and Murphy (2009) presented a general methodology for estimating break-even prices for Douglas-fir peeler logs that mills in Oregon, USA, could afford to pay based on acoustic assessment of veneer stiffness. Andersson et al. (2016) developed a mixed integer programming model that estimated the additional willingness of sawmills in Sweden to pay for logs of particular characteristics (length, SEDUB, knot type, and internode length). That study found that the additional costs associated with multiple log piles at the landing and separate transport of logs with different characteristics

Venn et al. (2020). "Log geometry for log procurement," BioResources 15(2), 2385-2411. 2386 
were not covered by increased willingness to pay. While a few studies have systematically examined how log diameter can affect the financial performance of veneer production (e.g., Dobner, Jr et al. 2013), the authors are not aware of papers that have attempted to systematically quantify how taper, sweep, and ovality of logs can affect the financial performance of veneer manufacture.

Table 1. Veneer Recovery by Grade from Research Trials where Spindleless Lathe Technology was Used

\begin{tabular}{|c|c|c|c|c|c|c|c|c|c|}
\hline \multirow{2}{*}{ Species } & \multirow{2}{*}{$\begin{array}{l}\text { Resource } \\
\text { Type }^{1}\end{array}$} & \multirow{2}{*}{$\begin{array}{l}\text { Age } \\
\text { (Years) }\end{array}$} & \multirow{2}{*}{$\begin{array}{c}\text { Mean } \\
\text { DBHOB } \\
(\mathrm{cm})^{2}\end{array}$} & \multirow{2}{*}{$\begin{array}{l}\text { Mean } \\
\text { Log } \\
\text { SEDUB } \\
(\mathrm{cm})^{3}\end{array}$} & \multirow{2}{*}{$\begin{array}{l}\text { NR } \\
(\%)^{4}\end{array}$} & \multicolumn{4}{|c|}{$\begin{array}{c}\text { Recovery By Veneer } \\
\text { Grade (\%) }\end{array}$} \\
\hline & & & & & & A & B & C & D \\
\hline $\begin{array}{l}\text { Corymbia } \\
\text { citriodora }\end{array}$ & $\mathrm{N}$ & & & 19.6 & 45 & 0 & 0 & 0 & 100 \\
\hline C. citriodora ${ }^{a}$ & $\mathrm{~N}$ & & & 23.7 & 48 & 0 & 9 & 5 & 86 \\
\hline C. citriodora ${ }^{\mathrm{a}}$ & $\mathrm{N}$ & & & 27.8 & 43 & 0 & 1 & 11 & 88 \\
\hline C. citriodorab & $\mathrm{P}$ & $\begin{array}{c}10 \text { to } \\
12\end{array}$ & 20.6 & 15.6 & 48 & 0.3 & 1 & 16.4 & 82.3 \\
\hline $\begin{array}{l}\text { Eucalyptus } \\
\text { cloezianab }^{\mathrm{b}}\end{array}$ & $\mathrm{P}$ & $\begin{array}{c}12 \text { to } \\
15\end{array}$ & 31.9 & 23.5 & 58 & 0.2 & 4.8 & 27.1 & 68 \\
\hline E. dunnil & $\mathrm{P}$ & 11 & 22.9 & 17.5 & 55 & 0 & 0 & 7.7 & 91.9 \\
\hline E. pellita & $\mathrm{P}$ & 13 & 28.1 & 20.9 & 55 & 0 & 1.5 & 10.4 & 86.1 \\
\hline E. nitens ${ }^{b}$ & $\mathrm{P}$ & $\begin{array}{l}20 \text { to } \\
22\end{array}$ & 34 & 28.9 & 55 & 0.4 & 9.1 & 13.7 & 76.9 \\
\hline E. globulus ${ }^{\text {b }}$ & $\mathrm{P}$ & $\begin{array}{c}13 \text { to } \\
16\end{array}$ & 30.6 & 25.7 & 50 & 0 & 0.9 & 2.3 & 96.8 \\
\hline
\end{tabular}

${ }^{1}$ Resource type, where $\mathrm{N}$ is native forest and $\mathrm{P}$ is plantation forest;

${ }^{2}$ Mean diameter at breast height over bark;

${ }^{3}$ Mean SEDUB of docked logs for veneering. Note that many trees produced more than one docked log for veneering.

${ }^{4}$ Net recovery of marketable veneer (\% of MDLV) ;

${ }^{5}$ Graded in accordance with AS/NZS 2269.0:2012 (2012);

Sources: aMcGavin and Leggate (2019); ' McGavin et al. (2014a)

The objectives of this study were to quantitatively and systematically investigate the effect of $\log$ dimensions and geometry (SEDUB, T, S, and O) on the recovery of marketable veneer from log volume for spindleless rotary veneer production and to produce a metric that will support log procurement decisions. The metric is the maximum that can be paid for mill-delivered logs of a particular log geometry while attaining a target gross margin (GM) that covers variable and fixed costs of veneering, including an acceptable return on invested capital. Gross margin is defined as the market value of marketable drygraded veneer minus the log cost. This paper describes a case study to support hardwood log procurement in Australia, and all dollar figures are reported in Australian dollars unless otherwise specified. In August 2019, the monetary conversion rate was $\$ 1=$ US $\$ 0.70$ (Reserve Bank of Australia 2019). Model parameters can easily be adjusted to accommodate alternative log resource type, business structure, and market scenarios. 


\section{EXPERIMENTAL}

\section{Materials and Methods}

The analysis was performed in four steps, namely:

1. Fit a regression model to predict total veneering time by rounded log diameter.

2. Determine net recovery of marketable veneer by log dimensions and geometry.

3. Predict the value of marketable veneer produced/h by rounded log diameter.

4. Calculate the maximum mill-delivered log cost for logs of alternative dimensions and geometries to achieve a target gross margin.

\section{Veneering time}

A time-and-motion study was performed during regular operations at a hardwood veneer manufacturing facility for a typical batch of 164 Eucalyptus species logs from native forests in subtropical eastern Australia. The logs had been steam-heated and docked to 2.6$\mathrm{m}$ length billets before they were loaded into the rounding-debarking lathe. This lathe removed geometrical irregularities such as sweep, taper, and ovality. Following rounding, the cylindrical billets ranged from $16 \mathrm{~cm}$ to $46 \mathrm{~cm}$ in diameter. The constraint on veneer production per unit of time was observed to be the spindleless rotary veneer lathe, not the rounder-debarking lathe. Therefore, measurement effort for the time-and-motion study was focused at the veneer lathe.

The rate at which the lathe can peel veneer is a function of the time spent loading logs into the lathe (LT) and the veneer peeling time (PT). Several variables not related to $\log$ dimensions and geometry, including machine operator skill, can affect the time spent loading logs into the lathe. However, log diameter is positively related to log loading time, because at the completion of peeling a log, the log drive rollers are closed at the peeler core position. The peeler core is a residual cylindrical core from the log centre, from which no veneer can be recovered. Lathe design often sets the minimum residual peeler core diameter. A minimum peeler core diameter of $4.5 \mathrm{~cm}$ was adopted in this study. The log drive rollers then need to retract from the closed position to provide a sufficient opening to allow the next log to enter the lathe in preparation for peeling. The larger the diameter of the next $\log$, the further the $\log$ drive rollers need to retract. The time required to retract the $\log$ drive rollers is greater than the time required for the log loader to position the next log ready for loading into the lathe, because the latter task is typically performed while peeling the log already in the lathe. Log loading time data was collected for the 164 logs, measured as the time from when peeling of one log stopped to when peeling of the next log commenced.

Theoretically, PT in s is a function of the rounded log diameter (RLD) of the cylindrical billets, lathe peeling speed (PS), veneer thickness (VT), and the core diameter (CD) as shown in Eq. 1:

$$
\mathrm{PT}=\pi \times \frac{\left[\left(\frac{\mathrm{RLD}}{2}\right)^{2}-\left(\frac{\mathrm{CD}}{2}\right)^{2}\right]}{\mathrm{VT} \times \mathrm{PS}}
$$

The PT was determined for the RLD for each of the 164 observed logs. The levels adopted and units for other variables in Eq. 1 are reported in Table 2. Total veneering time in s (TVT) for each of the 164 logs was then estimated as the sum of observed LT and the calculated PT, as shown in Eq. 2:

$$
\mathrm{TVT}=\mathrm{LT}+\mathrm{PT}
$$


Table 2. Log Geometry Characteristics Assessed and Rotary Spindleless Lathe Veneering Assumptions Adopted for Analysis

\begin{tabular}{|c|c|c|c|c|c|c|c|}
\hline Parameter & $\begin{array}{c}\text { Acronym } \\
\text { or } \\
\text { Svmbol }\end{array}$ & \multicolumn{6}{|c|}{ Levels Assessed } \\
\hline \multicolumn{8}{|c|}{ Log Geometry Characteristics } \\
\hline Log length $(m)$ & $L$ & \multicolumn{6}{|c|}{2.6} \\
\hline $\begin{array}{l}\text { Small-end diameter under bark } \\
(\mathrm{m})\end{array}$ & SEDUB & \multicolumn{6}{|c|}{$\begin{array}{l}\text { Range from } 0.16 \mathrm{~m} \text { to } 0.6 \mathrm{~m} \text { in } 0.02 \mathrm{~m} \\
\text { increments }\end{array}$} \\
\hline Taper $(\mathrm{m} / \mathrm{m})$ & $T$ & 0 & 0.005 & 0.01 & 0.02 & 0.04 & 0.08 \\
\hline Sweep $(\mathrm{m} / \mathrm{m})$ & $S$ & 0 & 0.005 & 0.01 & 0.02 & 0.04 & 0.08 \\
\hline $\begin{array}{l}\text { Ovality } \\
(\%)\end{array}$ & OV & 0 & 5 & 10 & 15 & 20 & \\
\hline \multicolumn{8}{|c|}{ Spindleless Lathe Veneering Assumptions } \\
\hline $\begin{array}{l}\text { Operating speed for spindleless } \\
\text { lathe }(\mathrm{Im} / \mathrm{s})\end{array}$ & PS & \multicolumn{6}{|c|}{0.667 (Equivalent to $40 \mathrm{Im} / \mathrm{min}$ ) } \\
\hline Peeler core diameter $(\mathrm{m})$ & CD & \multicolumn{6}{|c|}{0.045} \\
\hline $\begin{array}{c}\text { Peeler core volume for a } 2.6 \mathrm{~m} \\
\log \left(\mathrm{m}^{3}\right)\end{array}$ & CV & \multicolumn{6}{|c|}{0.004135} \\
\hline Veneer thickness (green) $(\mathrm{m})$ & VT & \multicolumn{6}{|c|}{0.0032} \\
\hline $\begin{array}{c}\text { Marketable veneer recovery from } \\
\text { peelable log volume }(\%)\end{array}$ & MVRPLV & \multicolumn{6}{|c|}{60} \\
\hline
\end{tabular}

Microsoft Excel (Microsoft Corp., version Microsoft Office Professional Plus 2016, Redmond, WA, USA) was used to fit a simple linear regression model to the TVT data to predict TVT as a function of RLD (in $\mathrm{cm}$ ). The model's fit to the data was tested with the F-test of overall significance, and the student t-test tested the significance of the slope of the regression. A measure of how well observed outcomes are replicated by the model is provided by the coefficient of determination. The TVT regression model assumed a lathe utilisation rate of $100 \%$. That is, logs were continuously being loaded and peeled in the lathe, and there were no stoppages due to issues such as log jams, waste removal, green veneer removal, or lathe knife sharpening. This is impossible in practice; however, utilization rates can vary substantially depending on many factors, including labour skill and level of processing automation. Results from this analysis were presented on the basis of $100 \%$ utilization, because it facilitated fractional adjustment of estimates to an alternative utilization rate. This was demonstrated in the discussion.

\section{Net recovery of marketable veneer}

Determining NR required information about the peelable log volume (PLV) that could potentially be recovered from MDLV. To facilitate a systematic analysis of the effect of log dimensions and geometry on NR, PLV in $\mathrm{m}^{3}$, in a cylindrical billet rounded from logs with taper $\left(\mathrm{PLV}_{\text {taper }}\right)$, sweep $\left(\mathrm{PLV}_{\text {sweep }}\right)$, and ovality $\left(\mathrm{PLV}_{\text {ovality }}\right)$ characteristics summarised in Table 2, was estimated for logs with SEDUB ranging from $0.16 \mathrm{~m}$ to $0.6 \mathrm{~m}$ in $0.02 \mathrm{~m}$ increments using the following equations,

$$
\mathrm{PLV}_{\text {taper }}=L \times \pi \times\left(\frac{\text { SEDUB }}{2}\right)^{2}-\mathrm{CV}
$$




$$
\begin{aligned}
& \mathrm{PLV}_{\text {sweep }}=L \times \pi \times\left(\frac{\text { SEDUB }-\mathrm{S} \times \mathrm{L}}{2}\right)^{2}-\mathrm{CV} \\
& \mathrm{PLV}_{\text {ovality }}=L \times \pi \times\left(\frac{\text { SEDUB }-\left(\frac{\mathrm{OV}}{2} \times \mathrm{SEDUB}\right)}{2}\right)^{2}-\mathrm{CV}
\end{aligned}
$$

where $L$ is log length (m), $\pi$ is the mathematical constant number $p i, \mathrm{CV}$ is the peeler core volume $\left(\mathrm{m}^{3}\right)$ where no veneer can be recovered, SEDUB is the small end-diameter under bark $(\mathrm{m})$ as measured by a diameter tape around the circumference of the log, $S$ is sweep in $\mathrm{m} / \mathrm{m}$ of log length, and OV is ovality as a percentage (\%) entered in the equation as a fraction. The variable OV was defined in Eq. 6,

$$
\mathrm{OV}=\frac{(L S E D U B-S S E D U B)}{S S E D U B}
$$

where LSEDUB is the largest small-end dimeter under bark $(\mathrm{m})$, as measured across the face of the small-end of the log, and SSEDUB is the smallest small-end dimeter under bark $(\mathrm{m})$, as measured across the face of the small-end of the log.

The variable MDLV, from which the PLV was obtained after rounding, was calculated as follows for logs with taper $\left(M D L V_{\text {taper }}\right)$, sweep $\left(M_{D L V} V_{\text {sweep }}\right)$, and ovality (MDLV $\mathrm{Mvality})$ characteristics reported in Table 2 as well as SEDUB ranging from $0.16 \mathrm{~m}$ to $0.6 \mathrm{~m}$ in $0.02 \mathrm{~m}$ increments,

$$
\begin{aligned}
& \mathrm{MDLV}_{\text {taper }}=L \times \frac{\pi}{4} \times\left(\frac{2 \times \text { SEDUB }+\mathrm{T} \times \mathrm{L}}{2}\right)^{2} \\
& \mathrm{MDLV}_{\text {sweep }}=L \times \pi \times\left(\frac{\text { SEDUB }}{2}\right)^{2} \\
& \mathrm{MDLV}_{\text {ovality }}=L \times \frac{\pi}{4} \times\left(\frac{\text { LSEDUB }+ \text { SSEDUB }}{2}\right)^{2}
\end{aligned}
$$

where $T$ is log taper in log length $(\mathrm{m} / \mathrm{m})$ and all other variables have been defined above.

Due to defects in the veneer sheets (from imperfections inside the log), shrinkage of veneer during drying, and trimming veneer to marketable dimensions, there were losses when processing green peeled veneer into recovered volume that met grade quality and was therefore marketable veneer. Hence, marketable veneer volume was less than PLV. The NR for logs ranging in SEDUB from $0.16 \mathrm{~m}$ to $0.6 \mathrm{~m}$ in $0.02 \mathrm{~m}$ increments is calculated as,

$$
\mathrm{NR}=\left(\frac{\mathrm{PLV}}{\mathrm{MDLV}}\right) \times \mathrm{MVRPLV}
$$

where PLV and MDLV are estimated using Eq. 3 to Eq. 9 for logs of alternative dimensions and geometry defined in Table 2, and MVRPLV is marketable veneer recovery from peelable log volume (\%).

There is limited available empirical data with which to estimate MVRPLV. This study assumed that green veneer was clipped to the desired sheet width, dried, and then visually graded in accordance with AS/NZS 2269.0:2012 (AS/NZS 2269.0:2012 2012) to produce marketable veneer that met D-grade criteria or better. The analysis assumed grade recovery per unit of green veneer was consistent regardless of log geometry. The manager of the facility at which the time-and-motion study was performed asserted $60 \%$ as an average, and that level was adopted in this analysis. 


\section{Volume and value of recoverable veneer}

Marketable veneer volume produced/h of peeling time (MVV) from logs ranging in SEDUB from $0.16 \mathrm{~m}$ to $0.6 \mathrm{~m}$ in $0.02 \mathrm{~m}$ increments was calculated as follows,

$$
\mathrm{MVV}=\frac{3600}{\mathrm{TVT}} \times \mathrm{PLV} \times \mathrm{MVRPLV}
$$

where 3600 is $1 \mathrm{~h}$ of time expressed in s, TVT is the total veneering time in s for a log of a particular RLD as predicted with the regression model, PLV is peelable log volume $\left(\mathrm{m}^{3}\right)$ from the rounded log estimated using Eq. 3, 4, or 5, as appropriate, and MVRPLV was $60 \%$.

Commercial dry-graded veneer values are challenging to determine, as veneer producers are typically manufacturing engineered wood products with the veneer, and the costs of production and final market prices for these products vary substantially. Information provided by industry key informants indicates that $3.0 \mathrm{~mm}$ (reduced from 3.2 $\mathrm{mm}$ green veneer through drying) D-grade plantation softwood veneer in Australia has a wholesale value of approximately $\$ 400 / \mathrm{m}^{3}$ (personal communication with Simon Dorries, Chief Executive Officer of Responsible Wood, May 2019). Dorries (2019) asserted that Cgrade veneer is approximately 1.2 times D-grade, B-grade is 1.7 times D-grade, and Agrade is 3 times D-grade. In the absence of wholesale market information for hardwood veneer in Australia, this study has adopted plantation softwood prices. The relative values for C, B, and A-grade veneers equate to $\$ 480 / \mathrm{m}^{3}, \$ 680 / \mathrm{m}^{3}$, and $\$ 1200 / \mathrm{m}^{3}$, respectively.

Veneer grade recoveries were assumed to be approximately the middle of the ranges reported in Table 1: A-grade at 0\%, B-grade at 5\%, C-grade at 15\%, and D-grade at $80 \%$. Marketable veneer value or revenue (R)/h of operation was estimated with Eq. 12,

$$
\mathrm{R}=\sum_{\mathrm{g}=\mathrm{A}}^{\mathrm{D}} \mathrm{MVV} \times \mathrm{GR}_{\mathrm{g}} \times \mathrm{P}_{\mathrm{g}}
$$

where $G R_{\mathrm{g}}$ is the veneer recovery by grade, $g(\%)$ and $P_{\mathrm{g}}$ is the market price for veneer grade, $g(\$)$.

\section{Maximum mill-delivered log cost to achieve a target gross margin}

The gross margin from sale of veneer produced from logs of particular log dimensions and geometries was defined as the value of marketable veneer produced minus the log cost. A useful metric to accommodate the impact of log dimensions and geometry on the financial performance of veneer manufacture and support log procurement decisions is the maximum that could be paid for mill-delivered logs of particular dimensions and geometry while achieving a target gross margin. Because log dimensions and geometry are expected to affect marketable veneer output per unit time, and a large proportion of operating costs (e.g., labour) vary with time, adopting a target gross margin $/ \mathrm{h}\left(\mathrm{GM} / \mathrm{h}_{\text {target }}\right)$ is appropriate. All non-log veneer manufacturing costs, including the desired profit margin, need to be covered by $\mathrm{GM} / \mathrm{h}_{\text {target. }}$. With a target gross margin determined, the maximum that can be paid for mill-delivered logs of a particular log dimension and geometry, MDLC $_{\max }$ (in $\$ / \mathrm{m}^{3}$ of $\log$ ), is estimated as follows,

$$
\mathrm{MDLC}_{\max }=\mathrm{R}-\frac{\mathrm{GM} \mathrm{h}_{\text {target }}{ }^{-1}}{\operatorname{MDLV} \times\left(\frac{(6000}{\mathrm{TVT}}\right)}
$$

where the denominator in the second term calculates the volume of mill-delivered logs of a particular log dimension and geometry processed/h. The variable TVT is for the RLD billet that will be produced from the log, as determined by the TVT regression model.

Venn et al. (2020). "Log geometry for log procurement," BioResources 15(2), 2385-2411. 2391 


\section{RESULTS AND DISCUSSION}

\section{Veneering time}

The mean rounded log diameter was $28 \mathrm{~cm}$, with $48 \%$ of the 164 observed logs in the range between $25 \mathrm{~cm}$ to $34 \mathrm{~cm}, 34 \%$ of the logs in the range between $16 \mathrm{~cm}$ and $24 \mathrm{~cm}$, and $18 \%$ in the range between $35 \mathrm{~cm}$ and $46 \mathrm{~cm}$. Observed LT ranged from $7.3 \mathrm{~s}$ to $21.3 \mathrm{~s}$, and RLD explained $23 \%$ of the variation in LT. The PT for the observed logs (calculated with Eq. 1) was added to LT to estimate TVT, which was plotted in Fig. 1, and ranged from 19.2 to 92.8 s. A statistically significant regression equation was found $(\mathrm{F}(1,162)=$ $3686.46, \mathrm{p}<0.001 ; \mathrm{t}=60.72, \mathrm{p}<0.001$ ), with an $\mathrm{R}^{2}$ of 0.958 . Total veneering time was equal to $[-25.641+2.423 \times \mathrm{RLD}]$, when RLD was measured in $\mathrm{cm}$.

\section{Net recovery of marketable veneer}

The NR from logs with SEDUB ranging from $16 \mathrm{~cm}$ to $60 \mathrm{~cm}$ was presented for logs with varying taper in Fig. 2, with varying sweep in Fig. 3, and with varying ovality in Fig. 4. The NR of cylindrical logs was asymptotic with MVRPLV. For a 2.6-m-long, 30$\mathrm{cm}$ SEDUB $\log$ with $0.01 \mathrm{~m} / \mathrm{m}$ taper, setting MVRPLV to $60 \%$ resulted in NR of $54 \%$ (calculated with Eq. 2, Eq. 5, and Eq. 10). This was comparable with NR estimates in Table 1, where mean taper and sweep across the studies were $0.0075 \mathrm{~m} / \mathrm{m}$ and $0.005 \mathrm{~m} / \mathrm{m}$, respectively.

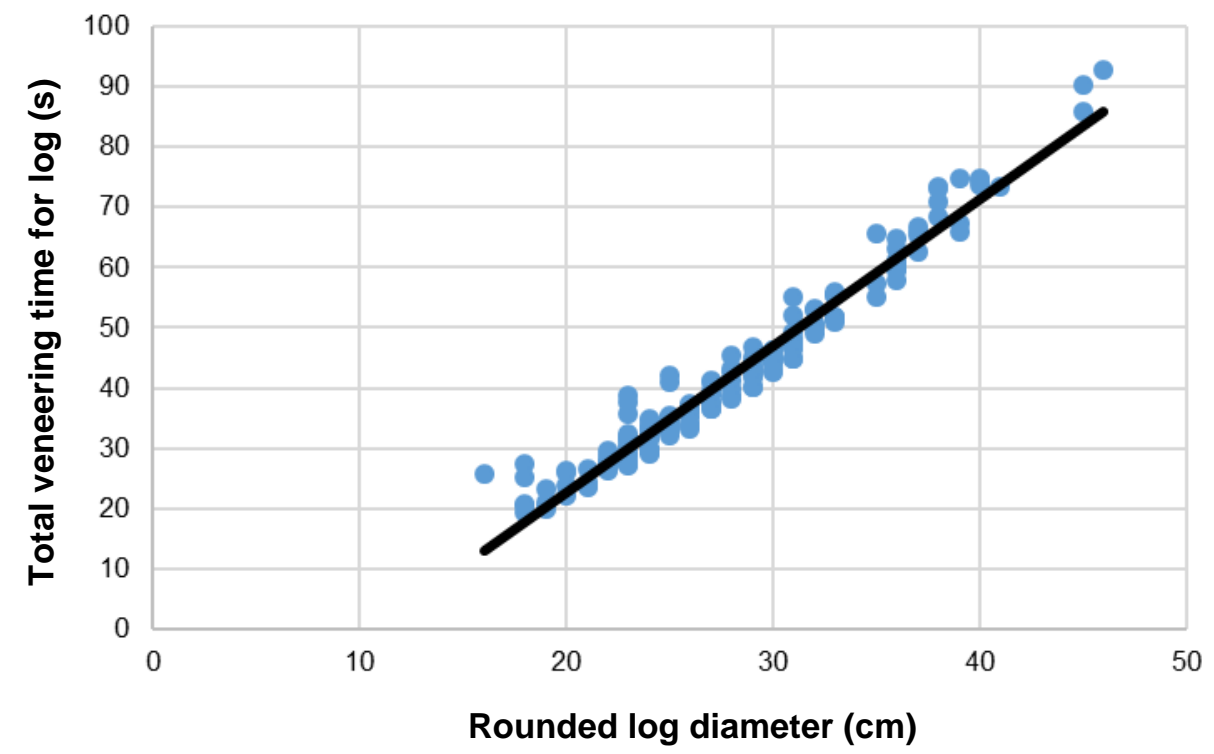

Fig. 1. TVT by RLD for 3.2-mm veneer peeled at $40 \mathrm{~lm} / \mathrm{min}$; observed values of TVT and the simple linear regression model are plotted

The results highlighted the positive relationship between log SEDUB and NR, and the negative relationship between NR and log taper, sweep, and ovality. For example, 49\% of $\log$ volume will be converted into marketable veneer from a 30-cm SEDUB log with $0.02 \mathrm{~m} / \mathrm{m}$ taper, relative to $59 \%$ from a cylindrical log with the same SEDUB. This meant that $20 \%$ less marketable veneer was produced from the log with taper. Sweep had the greatest impact on NR, and ovality had the least impact. 


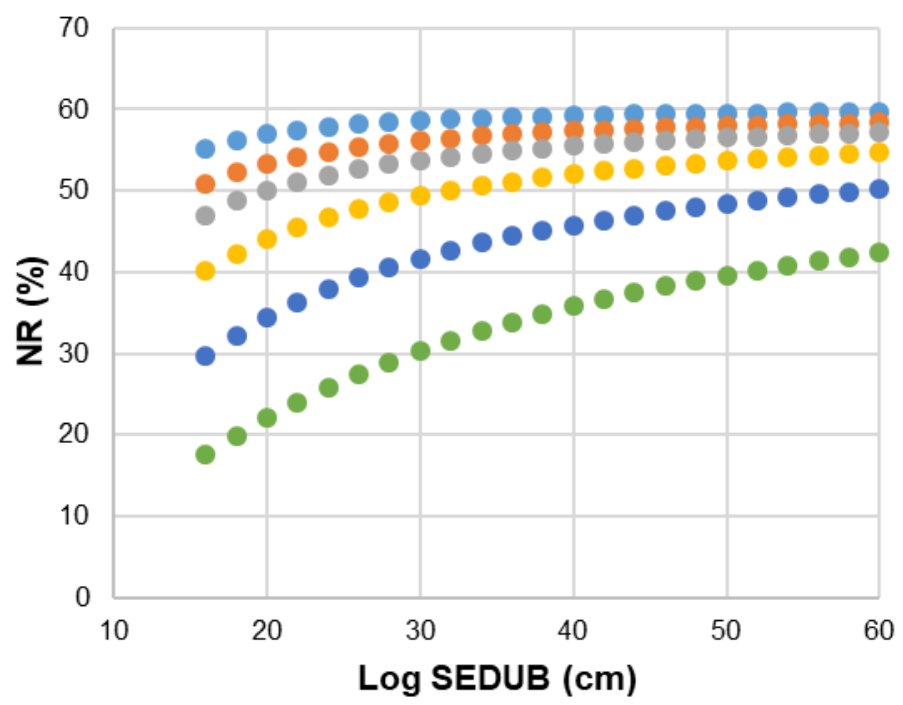

- Cylindrical log

$0.005 \mathrm{~m} / \mathrm{m}$ taper

$0.01 \mathrm{~m} / \mathrm{m}$ taper

$0.02 \mathrm{~m} / \mathrm{m}$ taper

$0.04 \mathrm{~m} / \mathrm{m}$ taper

$0.08 \mathrm{~m} / \mathrm{m}$ taper

Fig. 2. Net recovery of marketable veneer by SEDUB and $T$

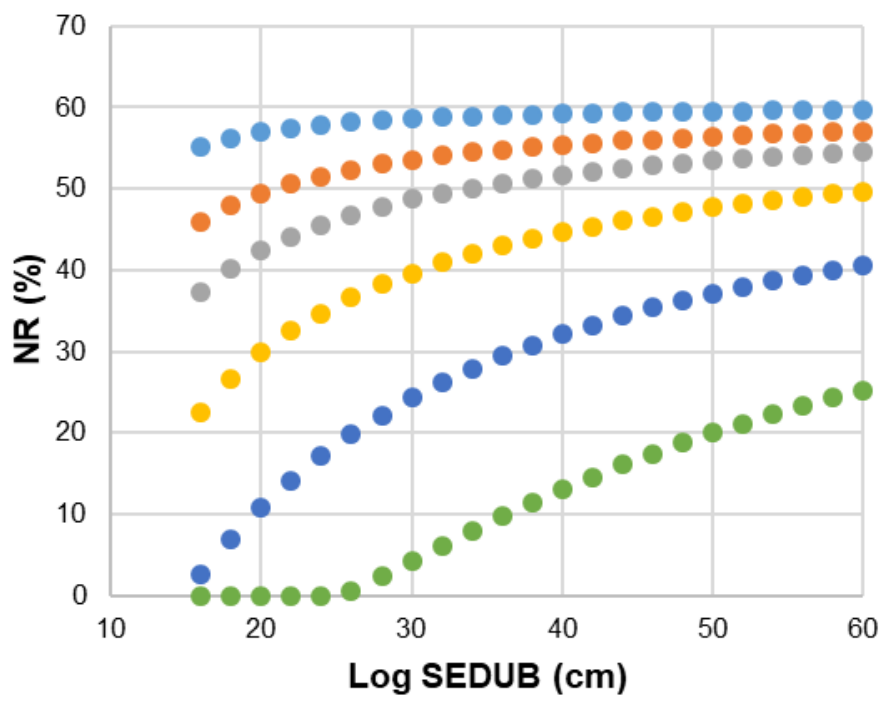

- Cylindrical log

$0.005 \mathrm{~m} / \mathrm{m}$ sweep

- $0.01 \mathrm{~m} / \mathrm{m}$ sweep

$0.02 \mathrm{~m} / \mathrm{m}$ sweep

- $0.04 \mathrm{~m} / \mathrm{m}$ sweep

- $0.08 \mathrm{~m} / \mathrm{m}$ sweep

Fig. 3. Net recovery of marketable veneer by SEDUB and S 


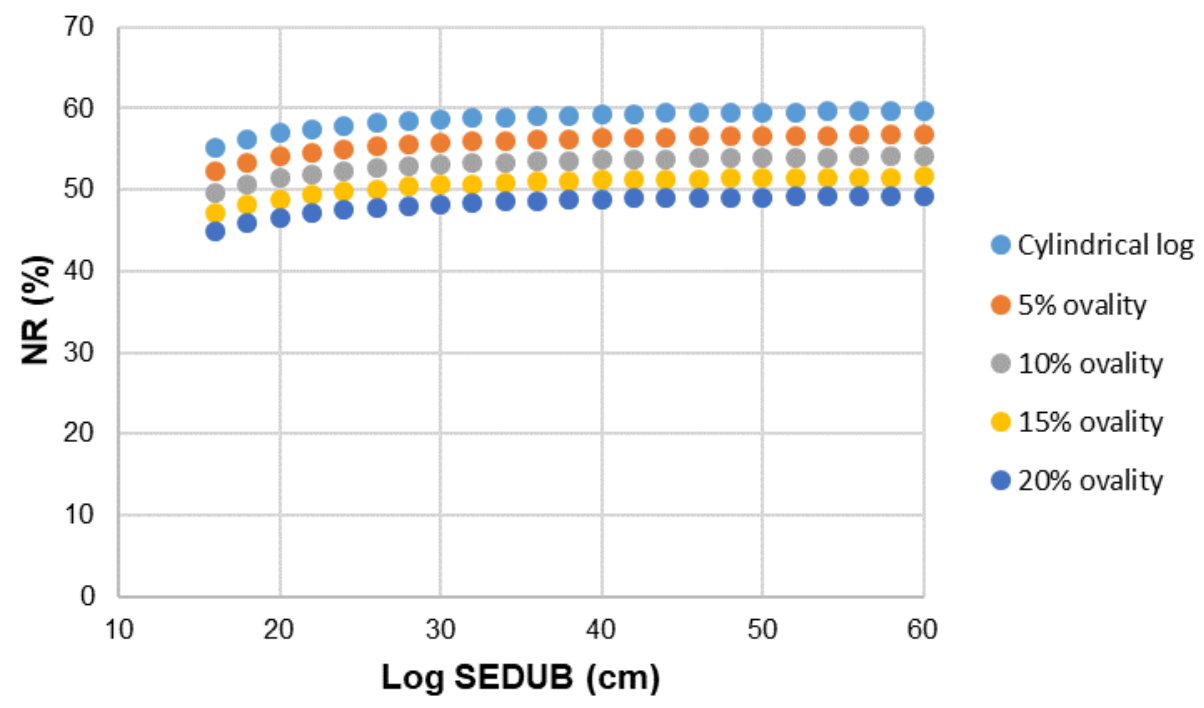

Fig. 4. Net recovery of marketable veneer by SEDUB and O

Volume and value of marketable veneer

The MVV and R are presented in Fig. 5 for RLD ranging from $16 \mathrm{~cm}$ to $60 \mathrm{~cm}$ and a $100 \%$ lathe utilisation rate. Values were extrapolated with the TVT regression model for logs exceeding $46 \mathrm{~cm}$ RLD (the largest observed log). Given the recovery of veneer by grade and the veneer prices by grade adopted for this study, the average value of marketable veneer $\left(\frac{\mathrm{R}}{\mathrm{MVV}}\right)$ was $\$ 426 / \mathrm{m}^{3}$. The MVV and $\mathrm{R}$ for alternative lathe utilisation rates could be estimated by multiplying the y-axes by the appropriate utilisation rate. The slightly Ushaped relationship of volume and value with RLD arose because of the short loading time for small rounded logs. As RLD increased, loading time increased, and for smaller RLD logs this additional loading time was not offset by the additional veneer volume produced from the $\log$. 


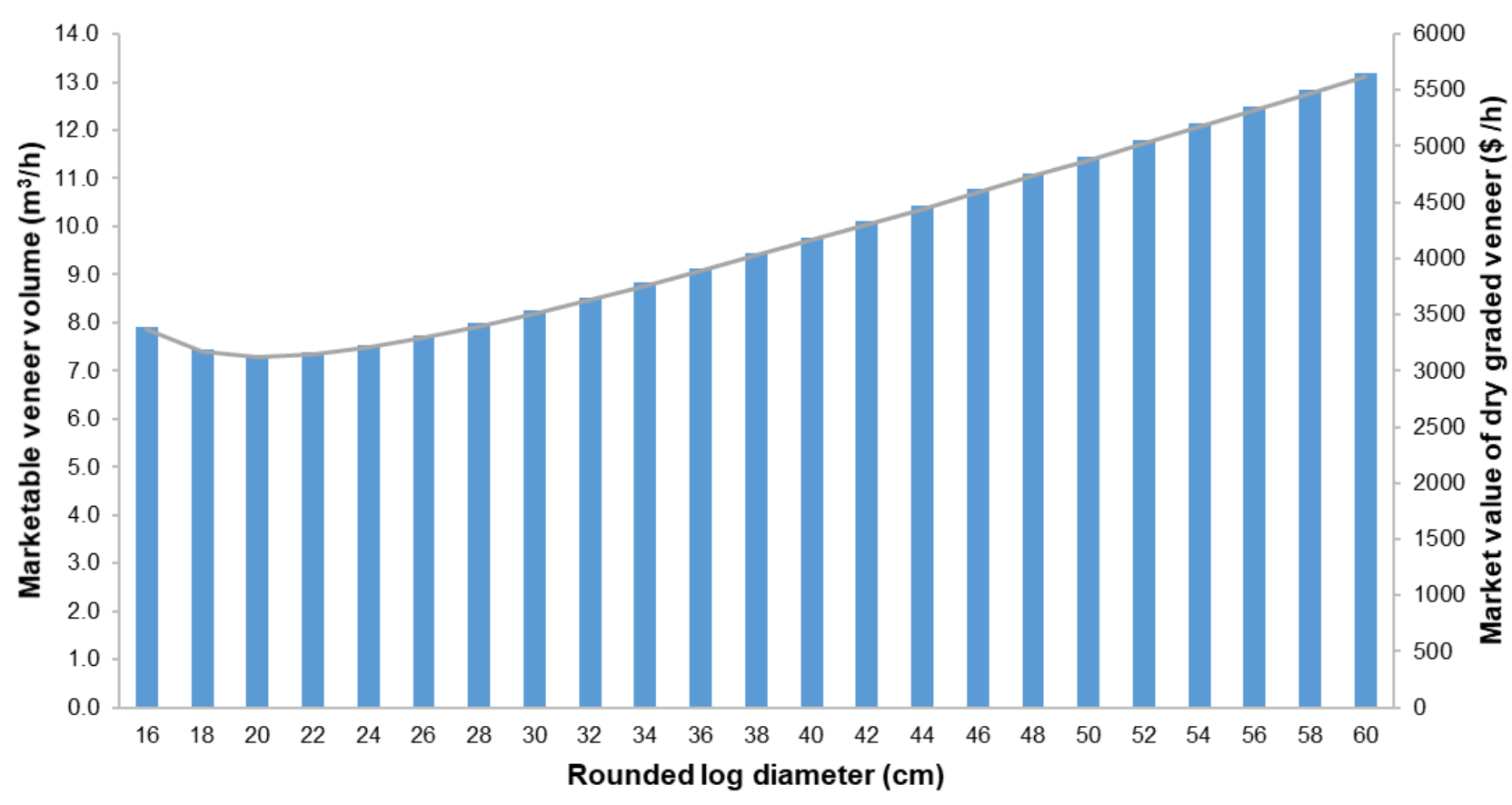

Marketable veneer volume

- Market value of dry graded veneer

Fig. 5. MVV (left axis), and market value of dry graded veneer produced (R) (right axis), by RLD; all $y$-axis data represent per $h$ of operation values

\section{Maximum mill-delivered log cost to achieve a target gross margin}

The effects of taper, sweep, and ovality on $\mathrm{MDLC}_{\max }$ are now each described in turn. The magnitude of the effect of SEDUB on MDLC $_{\max }$, relative to taper, sweep, and ovality, was also highlighted by reporting $\mathrm{MDLC}_{\max }$ for $20 \mathrm{~cm}, 30 \mathrm{~cm}, 40 \mathrm{~cm}, 50 \mathrm{~cm}$, and $60 \mathrm{~cm}$ SEDUB logs.

\section{Impact of log taper}

Figure 6 illustrates the impact of taper on $\mathrm{MDLC}_{\max }$ for a lathe utilization rate of $100 \%$. Panel (a) presents MDLC $_{\max }$ for cylindrical logs. For example, to earn gross margins of $\$ 1000 / \mathrm{h}$ (i.e., $\mathrm{GM} / \mathrm{h}_{\text {target }}=\$ 1000$ ), the maximum that can be paid for $20 \mathrm{~cm}$ SEDUB logs is $\$ 165 / \mathrm{m}^{3}$, and the maximum for $60 \mathrm{~cm}$ SEDUB $\operatorname{logs}$ is $\$ 209 / \mathrm{m}^{3}$. The MDLC $\mathrm{Cax}_{\max }$ increased with SEDUB because the proportion of log volume that was peelable was higher for larger SEDUB logs (Fig. 2), and because a larger volume of larger SEDUB logs could be processed per unit of time (Fig. 5).

The remaining panels in Fig. 6 present MDLC $_{\max }$ for increasing levels of log taper. For example, to achieve gross margins of $\$ 2000 / \mathrm{h}$, the $\mathrm{MDLC}_{\max }$ for mill-delivered logs with $0.01 \mathrm{~m} / \mathrm{m}$ taper (panel c) was approximately $\$ 10 / \mathrm{m}^{3}$ less than for logs of the same SEDUB with zero taper. 


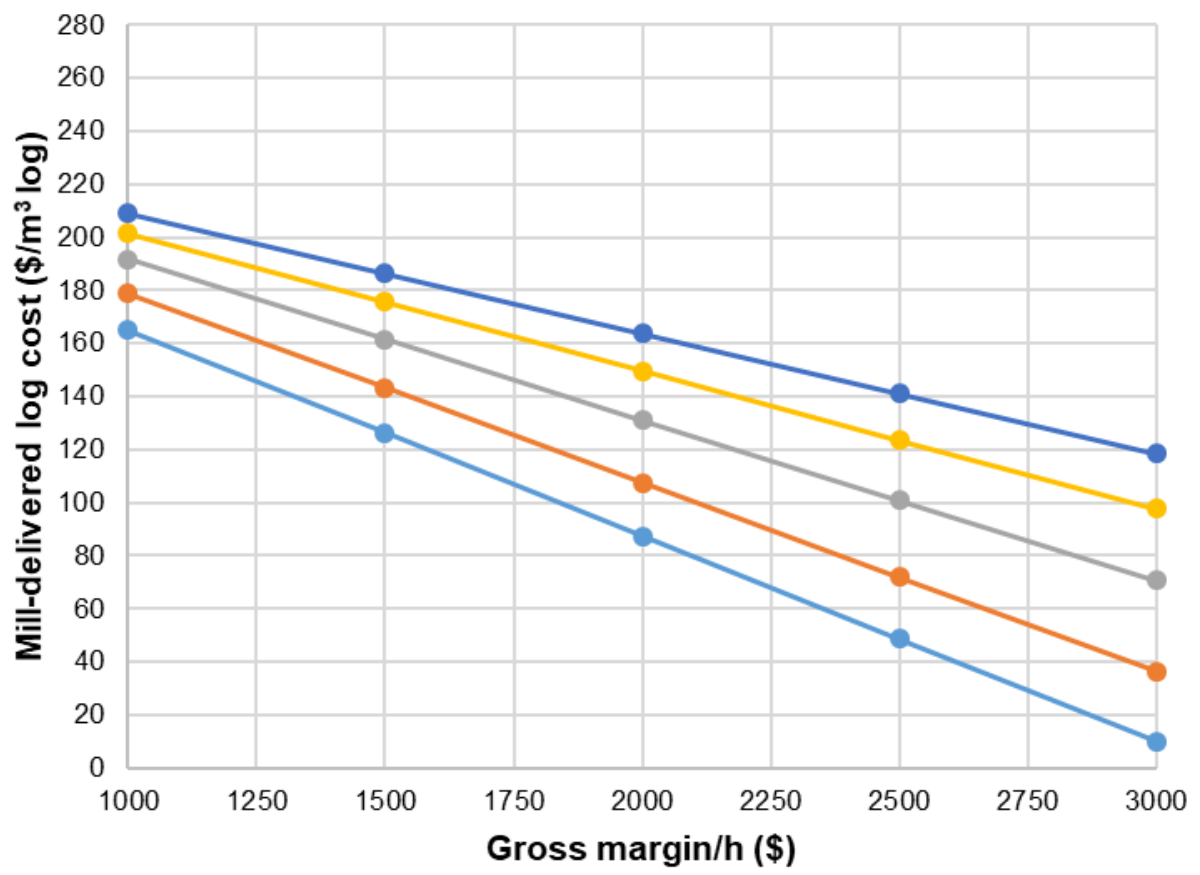

-SEDUB $20 \mathrm{~cm} \longrightarrow$ SEDUB $30 \mathrm{~cm} \longrightarrow$ SEDUB $40 \mathrm{~cm}$

$\multimap$ SEDUB $50 \mathrm{~cm} \longrightarrow$ SEDUB $60 \mathrm{~cm}$

(a)

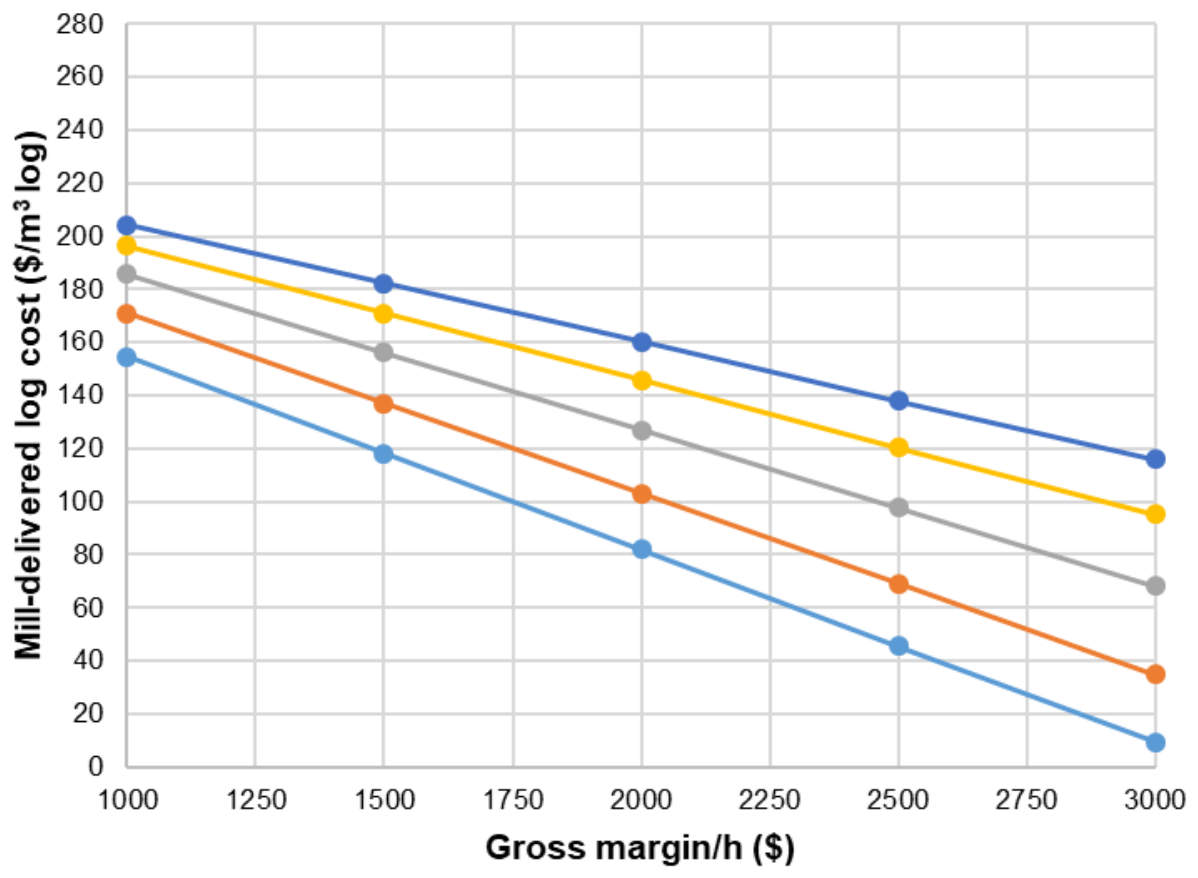

$\longrightarrow$ SEDUB $20 \mathrm{~cm} \longrightarrow$ SEDUB $30 \mathrm{~cm} \longrightarrow$ SEDUB $40 \mathrm{~cm}$

$\longrightarrow$ SEDUB $50 \mathrm{~cm} \longrightarrow$ SEDUB $60 \mathrm{~cm}$

(b) 


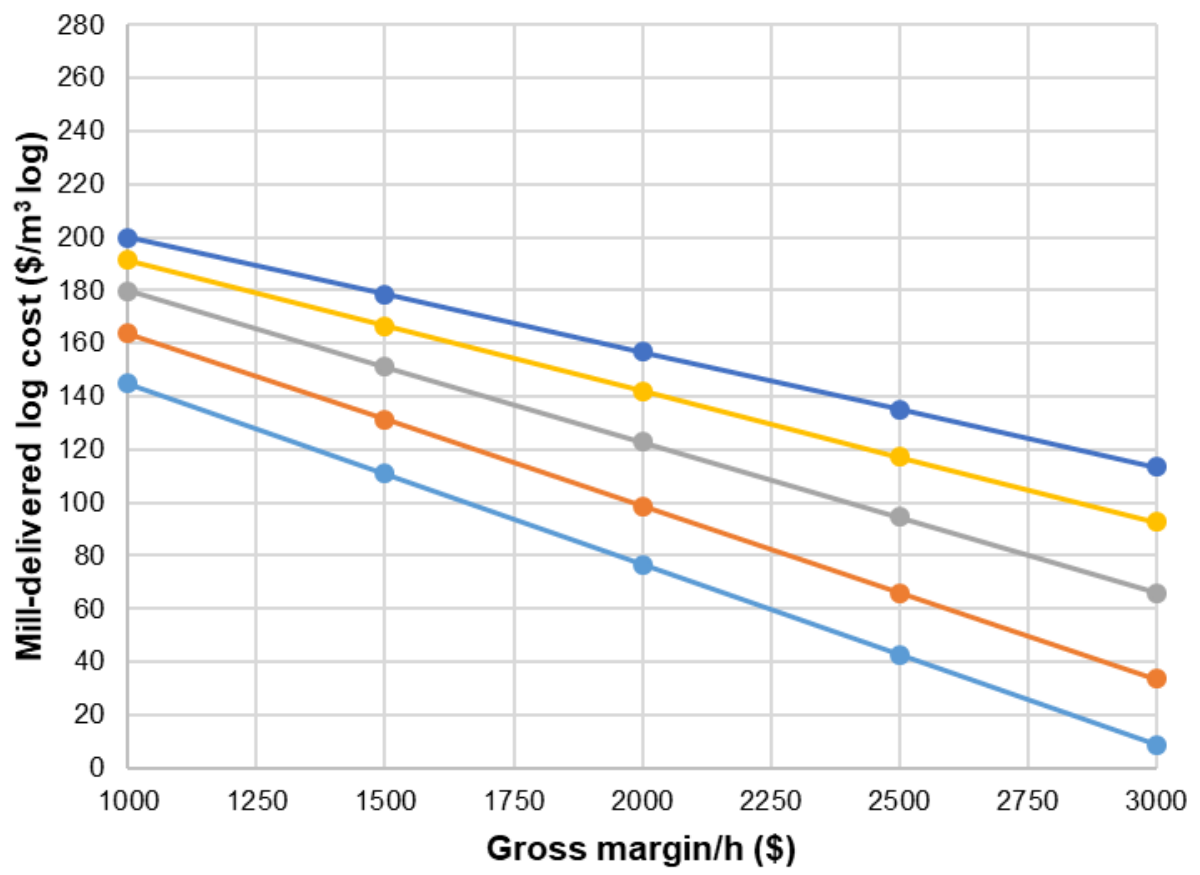

$\longrightarrow$ SEDUB $20 \mathrm{~cm} \longrightarrow$ SEDUB $30 \mathrm{~cm} \longrightarrow$ SEDUB $40 \mathrm{~cm}$

$\multimap$ SEDUB $50 \mathrm{~cm} \longrightarrow$ SEDUB $60 \mathrm{~cm}$

(c)

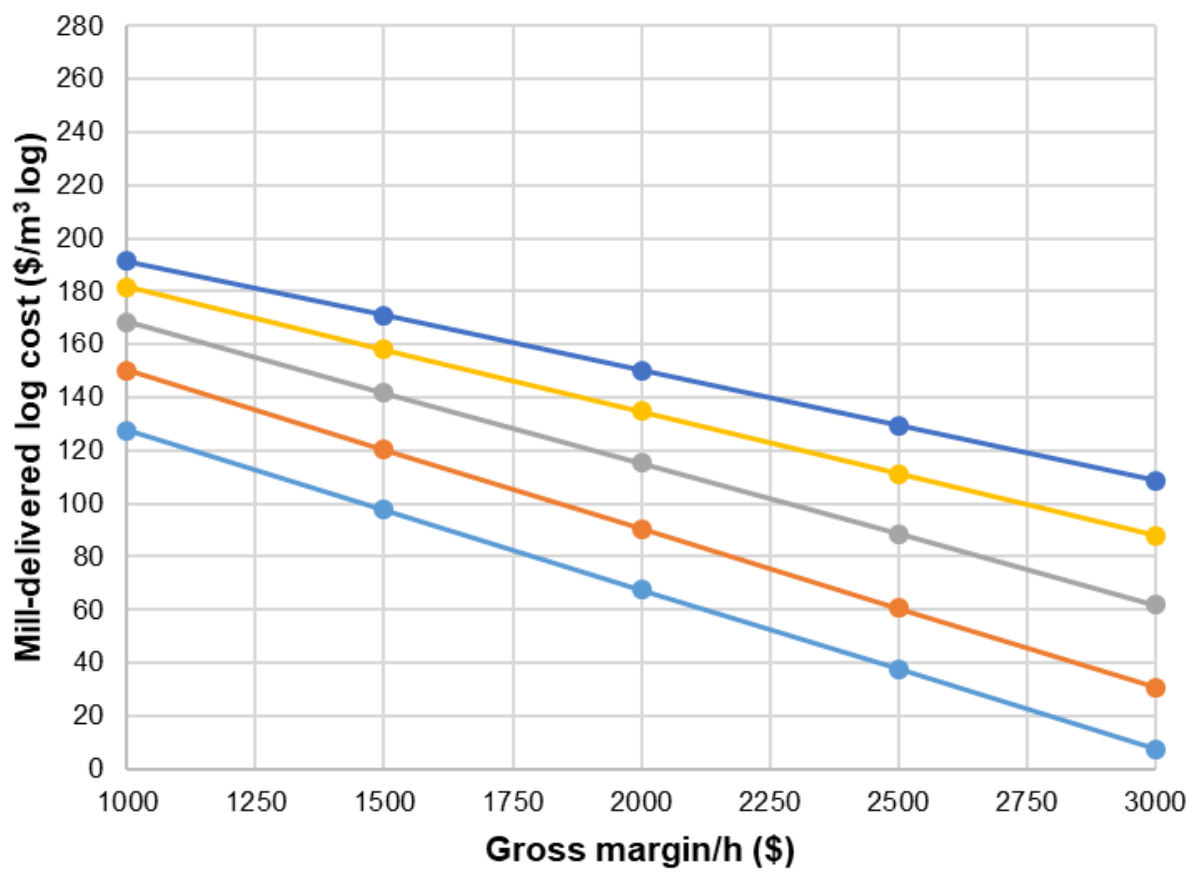

$\longrightarrow$ SEDUB $20 \mathrm{~cm} \longrightarrow$ SEDUB $30 \mathrm{~cm} \longrightarrow$ SEDUB $40 \mathrm{~cm}$

$\longrightarrow$ SEDUB $50 \mathrm{~cm} \longrightarrow$ SEDUB $60 \mathrm{~cm}$

(d) 

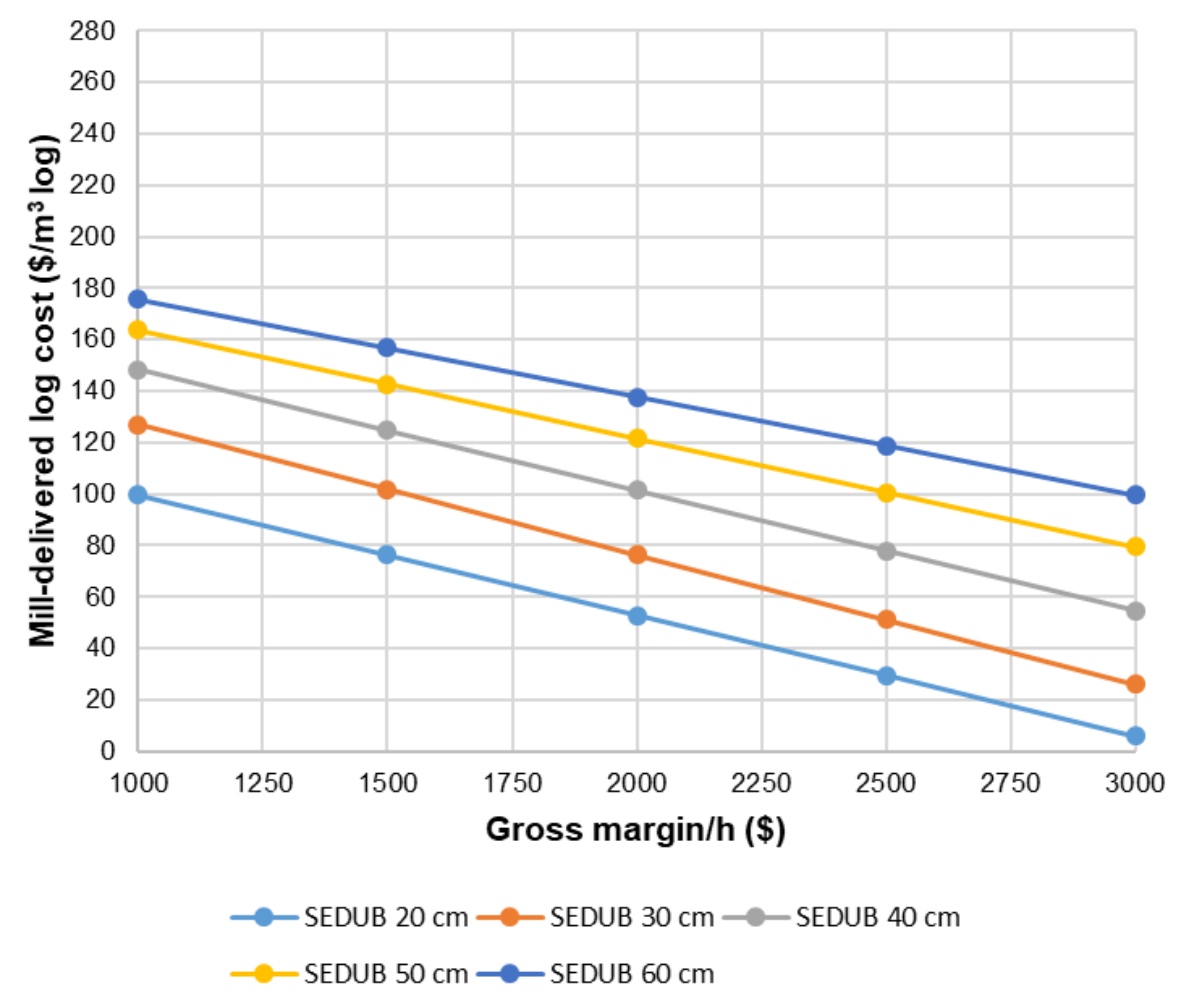

(e)

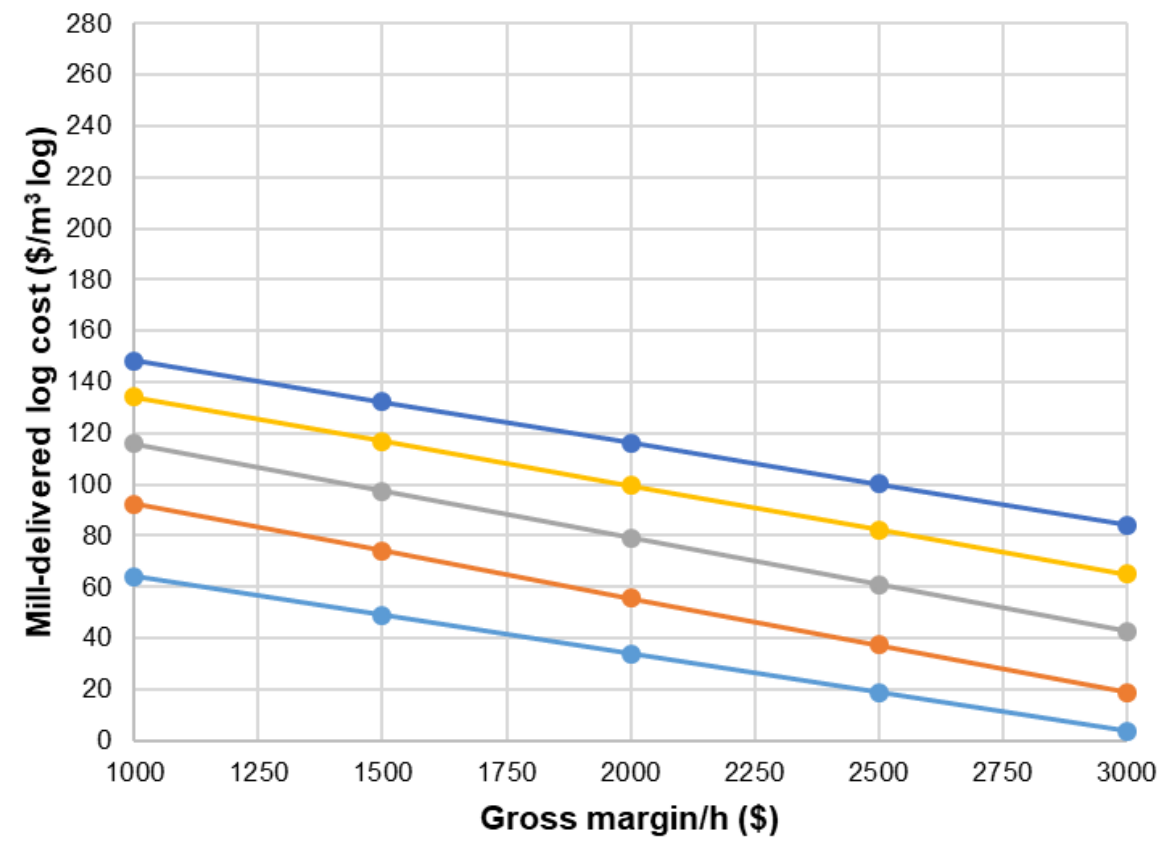

$$
\begin{aligned}
& \longrightarrow \text { SEDUB } 20 \mathrm{~cm} \longrightarrow \text { SEDUB } 30 \mathrm{~cm} \longrightarrow \text { SEDUB } 40 \mathrm{~cm} \\
& \longrightarrow \text { SEDUB } 50 \mathrm{~cm} \longrightarrow \text { SEDUB } 60 \mathrm{~cm}
\end{aligned}
$$

(f)

Fig. 6. Impact of taper on maximum mill-delivered log cost to achieve particular gross margins $/ \mathrm{h}$; Notes: (a) cylindrical log, (b) $0.005 \mathrm{~m} / \mathrm{m}$ taper, (c) $0.01 \mathrm{~m} / \mathrm{m}$ taper, (d) $0.02 \mathrm{~m} / \mathrm{m}$ taper, (e) $0.04 \mathrm{~m} / \mathrm{m}$ taper, and (f) $0.08 \mathrm{~m} / \mathrm{m}$ taper 
At a gross margin of $\$ 2000 / \mathrm{h}$, the $\mathrm{MDLC}_{\max }$ for $\operatorname{logs}$ with $0.08 \mathrm{~m} / \mathrm{m}$ taper was approximately $\$ 50 / \mathrm{m}^{3}$ lower than for logs with zero taper. To put this into context, a 2.6m-long, 20-cm SEDUB $\log$ with $0.08 \mathrm{~m} / \mathrm{m}$ taper would have a LEDUB of $40.8 \mathrm{~cm}$. Thus, much waste would be generated when rounding the log to the SEDUB and utilising such logs would only be financially viable at much lower log costs.

Close examination of Fig. 6 revealed that SEDUB had a greater effect on MDLC $\max$ than taper. This was indicated by how the difference in $\mathrm{MDLC}_{\max }$ between $20 \mathrm{~cm}$ and 60 $\mathrm{cm}$ SEDUB logs in panel (a) was greater than the difference in $\mathrm{MDLC}_{\max }$ between $\operatorname{logs}$ with zero taper (panel a) and $0.08 \mathrm{~m} / \mathrm{m}$ taper (panel f) for a particular SEDUB when the gross margin was greater than $\$ 1000 / \mathrm{h}$.

Interpretation of Fig. 6 could be adjusted to reflect any lathe utilization rate. For example, if the lathe utilization rate was actually $50 \%$, then the gross margins on the $\mathrm{x}$-axis are halved. To earn a gross margin of $\$ 500 / \mathrm{h}$ in that case, $\mathrm{MDLC}_{\max }$ for $20 \mathrm{~cm}$ SEDUB cylindrical logs must be $\$ 165 / \mathrm{m}^{3}$, and $\mathrm{MDLC}_{\max }$ for $60 \mathrm{~cm}$ SEDUB cylindrical logs must be $\$ 209 / \mathrm{m}^{3}$.

\section{Impact of sweep}

Figure 7 illustrates the impact of sweep on MDLC $_{\max }$, where panel (a) presents the cylindrical log case. Mill-delivered log costs for any particular gross margin were considerably lower for logs with sweep than for logs with the same level of taper. This was because of the much greater impact of sweep on NR, as highlighted by comparing Fig. 2 and Fig. 3. For example, MDLC $_{\max }$ for $20 \mathrm{~cm}$ and $60 \mathrm{~cm}$ SEDUB $\operatorname{logs}$ with $0.01 \mathrm{~m} / \mathrm{m}$ sweep at a gross margin of $\$ 2000 / \mathrm{h}$ were $\$ 19 / \mathrm{m}^{3}$ and $\$ 17 / \mathrm{m}^{3}$ lower than for cylindrical logs, respectively. At $0.04 \mathrm{~m} / \mathrm{m}$ sweep, positive gross margins could not be earned with $20 \mathrm{~cm}$ SEDUB logs, and MDLC $_{\max }$ for a 60 -cm SEDUB log while earning a gross margin of $\$ 2000 / \mathrm{h}$ was $\$ 62 / \mathrm{m}^{3}$ lower than for a cylindrical log. At $0.08 \mathrm{~m} / \mathrm{m}$ sweep, positive gross margins could not be earned with 30-cm SEDUB logs.

In Fig. 7, panel (d), the mill-delivered log cost schedule for 20-cm SEDUB logs was noticeably flatter than for larger SEDUB logs. This occurred because 20-cm SEDUB mill-delivered logs with $0.02 \mathrm{~m} / \mathrm{m}$ sweep were rounded to only $14.8 \mathrm{~cm}$ for peeling, which resulted in considerably shorter predicted total veneering time $/ \mathrm{m}^{3}$ of veneer (from the TVT regression model) than for larger mill-delivered logs.

Figure 7 suggests that sweep had a greater effect on MDLC $_{\max }$ than SEDUB. The difference in MDLC $_{\max }$ between 20-cm and 60-cm SEDUB logs in panel (a) was less than the difference in MDLC $_{\max }$ between logs with zero taper (panel a) and $0.08 \mathrm{~m} / \mathrm{m}$ sweep (panel f), although they had the same SEDUB.

\section{Impact of ovality}

Figure 8 illustrates the impact of ovality on $\mathrm{MDLC}_{\max }$. For the levels of ovality examined, the level of impact was small relative to the projected impact of taper and sweep, and this was explained by the relatively high NR from logs with ovality (compare Fig. 2, Fig. 3, and Fig. 4). At $20 \%$ ovality (panel e), MDLC $\max$ for $20-\mathrm{cm}$ SEDUB logs while maintaining $\$ 2000 / \mathrm{h}$ gross margin was $\$ 14 / \mathrm{m}^{3}$ lower than for cylindrical logs (panel a). This was similar to the level of impact on MDLC $_{\max }$ for $20-\mathrm{cm}$ SEDUB $\operatorname{logs}$ with $0.01 \mathrm{~m} / \mathrm{m}$ sweep or $0.02 \mathrm{~m} / \mathrm{m}$ taper. The difference in MDLC $_{\max }$ between $20 \%$ ovality and cylindrical $60-\mathrm{cm}$ SEDUB $\operatorname{logs}$ was $\$ 35 / \mathrm{m}^{3}$. This was similar to the level of impact on $\mathrm{MDLC}_{\max }$ for $60-\mathrm{cm}$ SEDUB logs with $0.02 \mathrm{~m} / \mathrm{m}$ sweep or $0.04 \mathrm{~m} / \mathrm{m}$ taper. 
Figure 8 also reveals that SEDUB had a greater effect on MDLC $_{\max }$ than ovality. This was indicated by how the difference in MDLC $_{\max }$ between 20-cm and 60-cm SEDUB logs in panel (a) was greater than the difference in MDLC $_{\max }$ between $\operatorname{logs}$ with zero ovality (panel a) and $20 \%$ ovality (panel e), although they had the same SEDUB.
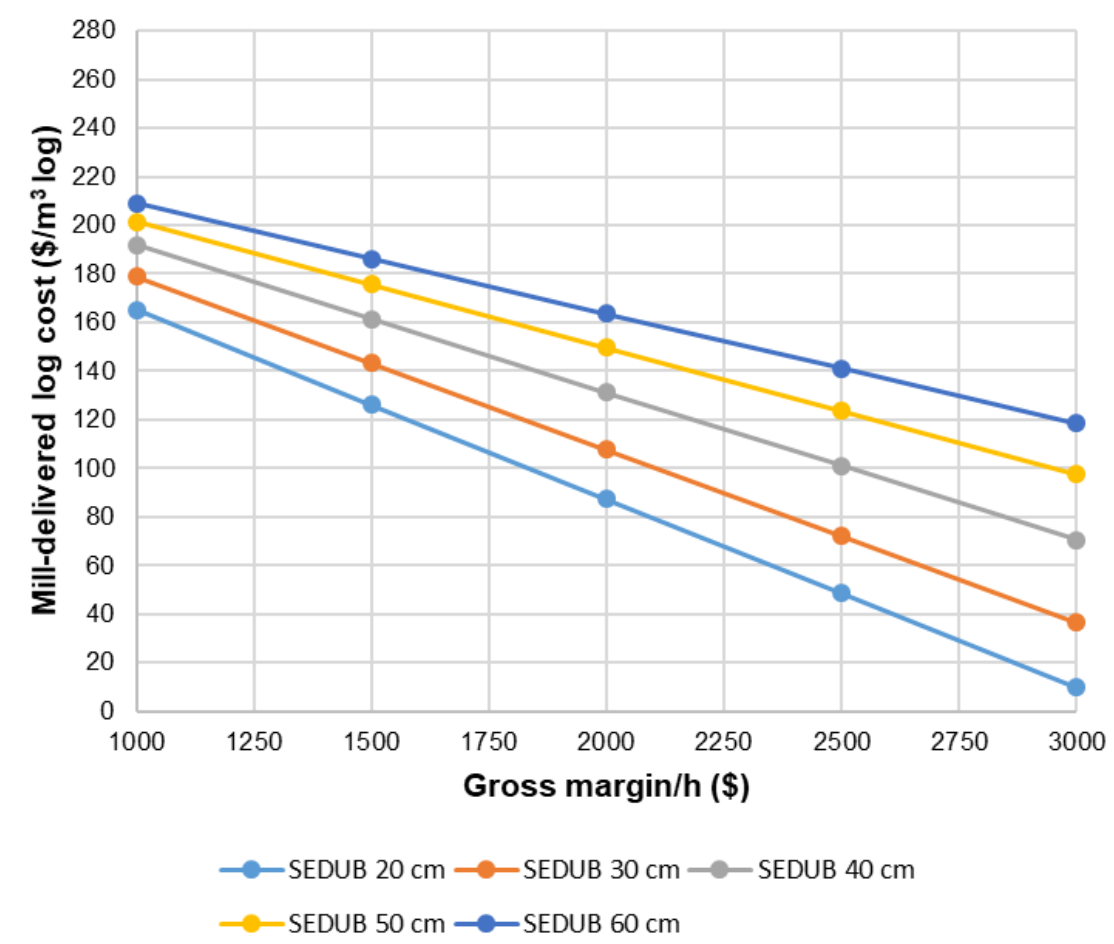

(a)

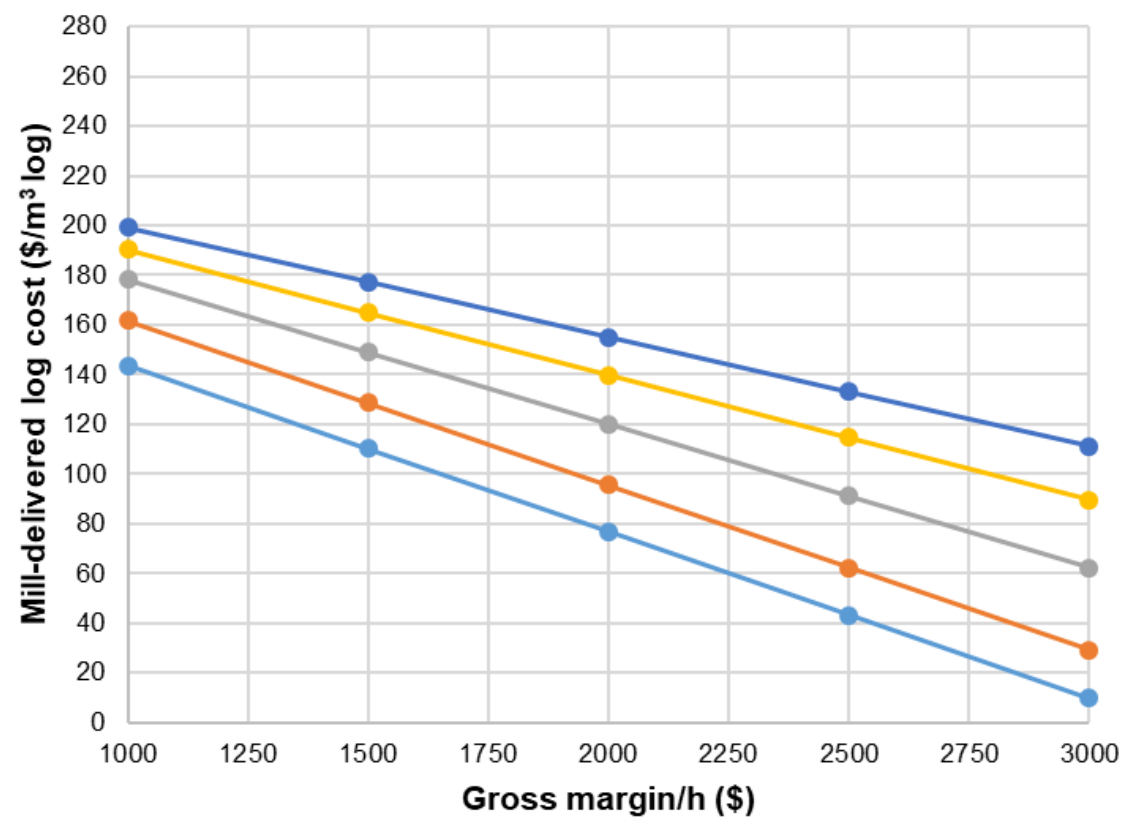

$\longrightarrow$ SEDUB $20 \mathrm{~cm} \longrightarrow$ SEDUB $30 \mathrm{~cm} \longrightarrow$ SEDUB $40 \mathrm{~cm}$

$\longrightarrow$ SEDUB $50 \mathrm{~cm} \longrightarrow$ SEDUB $60 \mathrm{~cm}$

(b) 

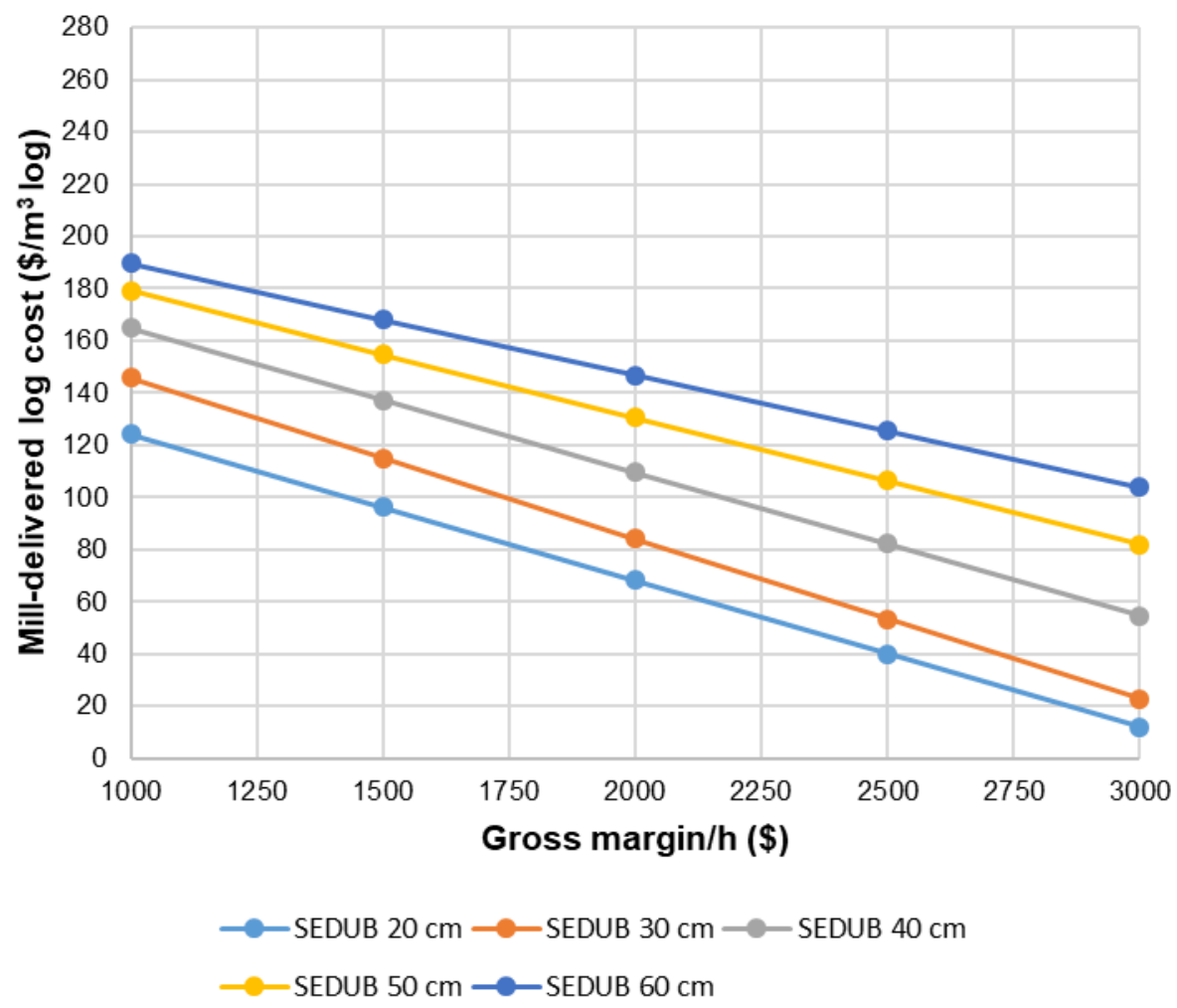

(c)

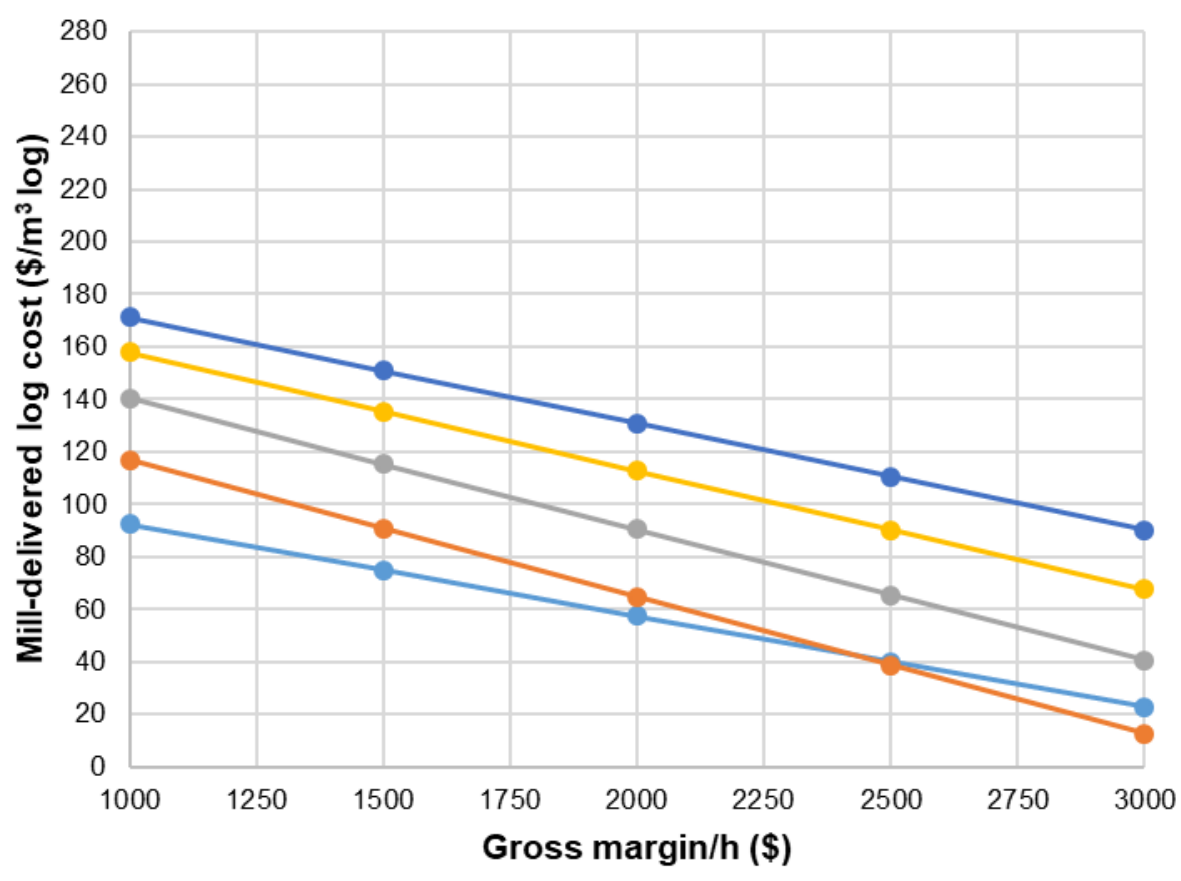

$\longrightarrow$ SEDUB $20 \mathrm{~cm} \longrightarrow$ SEDUB $30 \mathrm{~cm} \longrightarrow$ SEDUB $40 \mathrm{~cm}$

$\multimap$ SEDUB $50 \mathrm{~cm} \longrightarrow$ SEDUB $60 \mathrm{~cm}$

(d) 

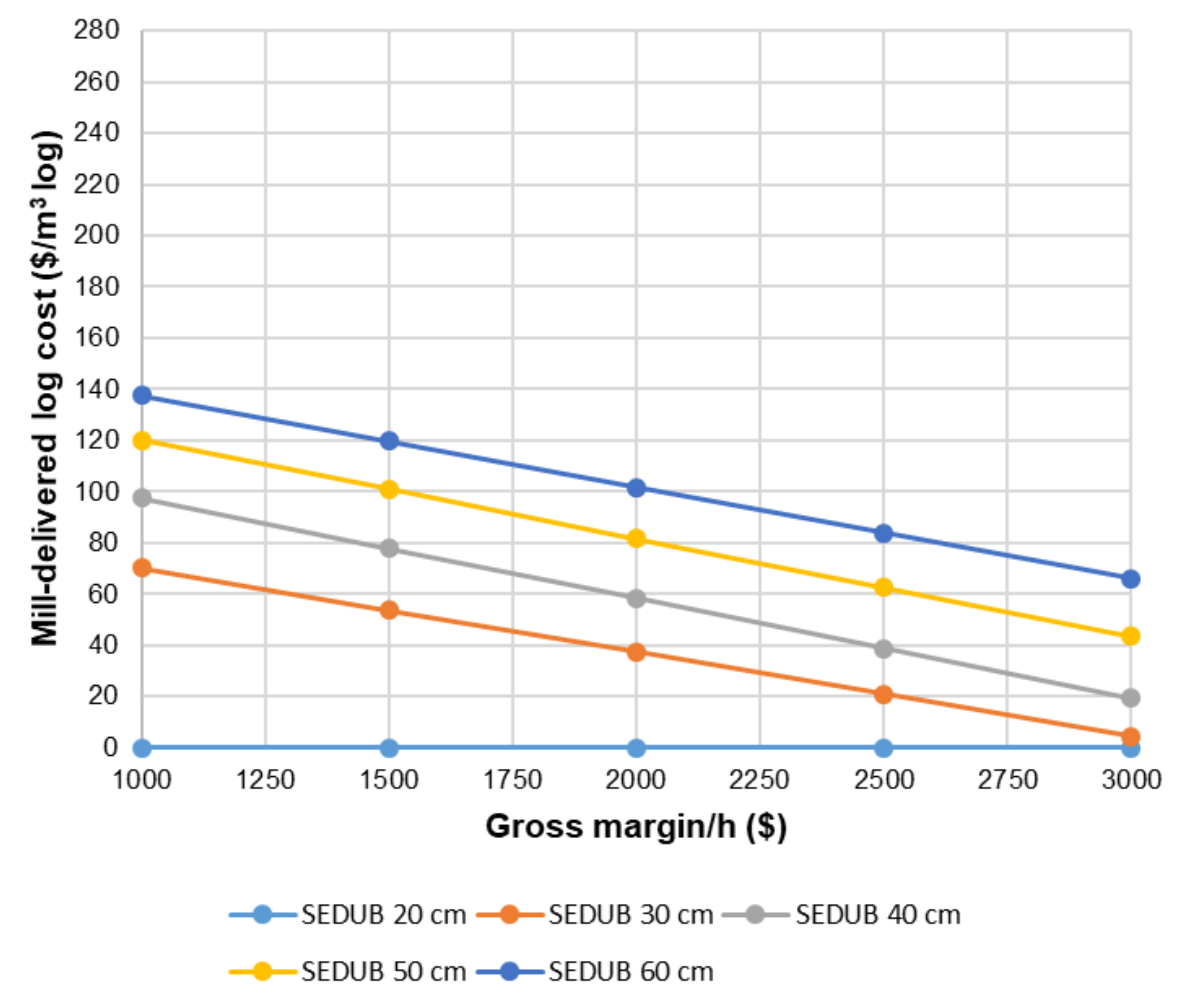

(e)

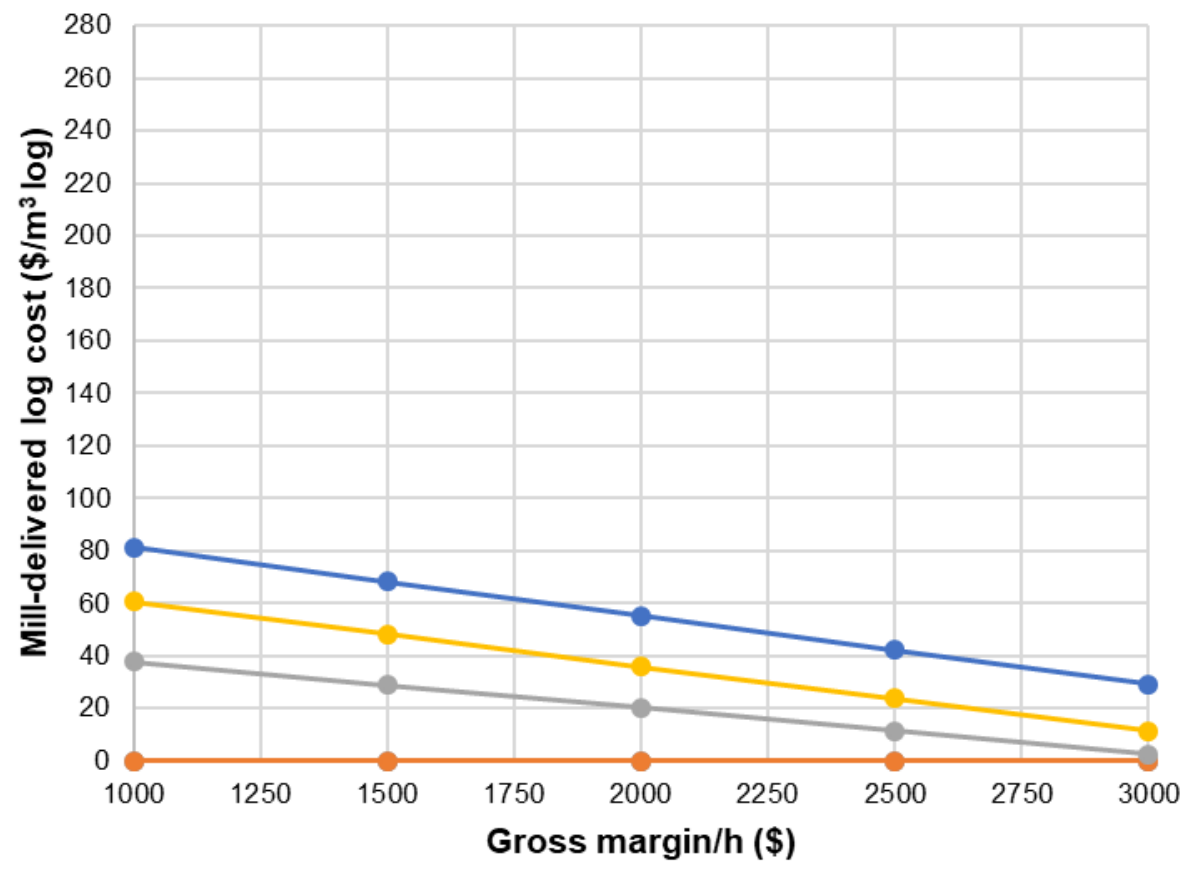

$$
\begin{aligned}
& \longrightarrow \text { SEDUB } 20 \mathrm{~cm} \longrightarrow \text { SEDUB } 30 \mathrm{~cm} \longrightarrow \text { SEDUB } 40 \mathrm{~cm} \\
& \longrightarrow \text { SEDUB } 50 \mathrm{~cm} \longrightarrow \text { SEDUB } 60 \mathrm{~cm}
\end{aligned}
$$

(f)

Fig. 7. Impact of sweep on maximum mill-delivered log cost to achieve particular gross margins $/ \mathrm{h}$; Notes: (a) cylindrical log, (b) $0.005 \mathrm{~m} / \mathrm{m}$ sweep, (c) $0.01 \mathrm{~m} / \mathrm{m}$ sweep, (d) $0.02 \mathrm{~m} / \mathrm{m}$ sweep, (e) $0.04 \mathrm{~m} / \mathrm{m}$ sweep, and (f) $0.08 \mathrm{~m} / \mathrm{m}$ sweep 


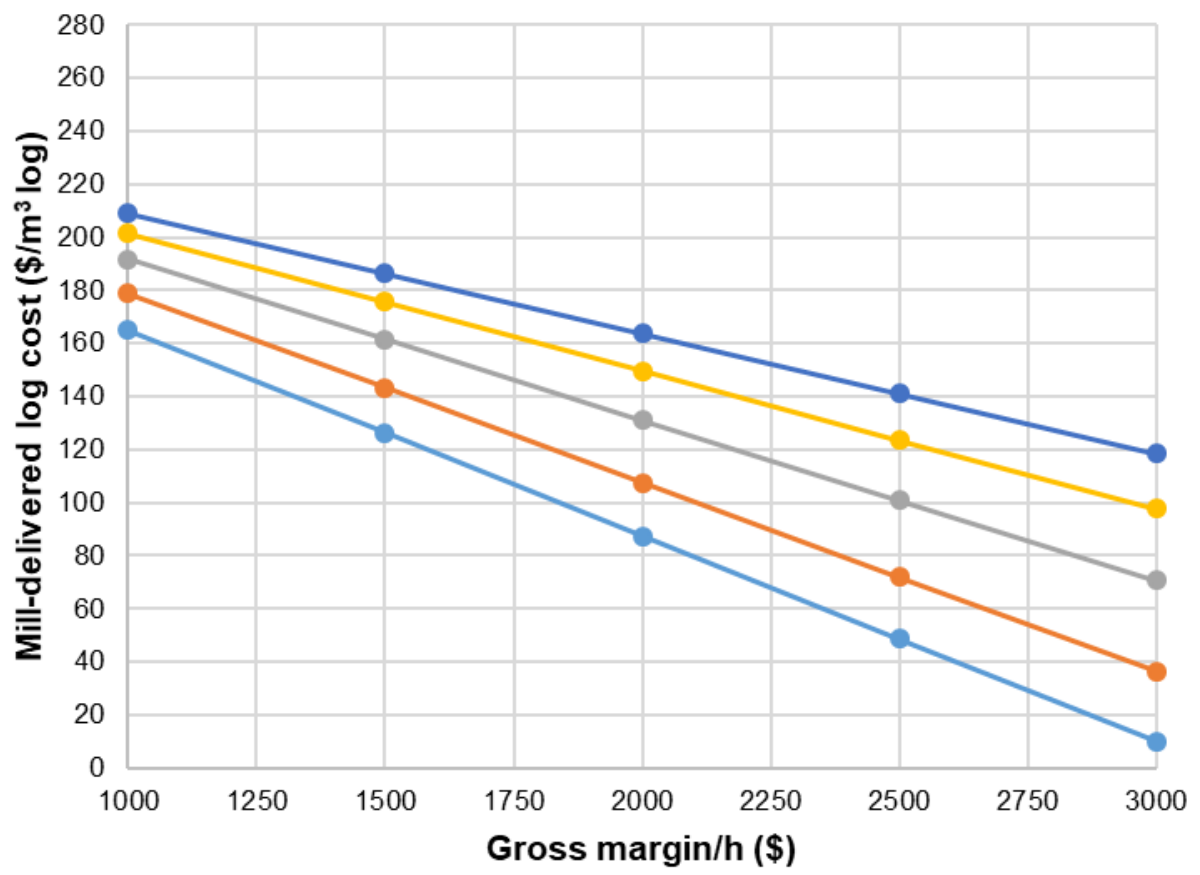

—SEDUB $20 \mathrm{~cm} \longrightarrow$ SEDUB $30 \mathrm{~cm} \longrightarrow$ SEDUB $40 \mathrm{~cm}$

$\multimap$ SEDUB $50 \mathrm{~cm} \longrightarrow$ SEDUB $60 \mathrm{~cm}$

(a)

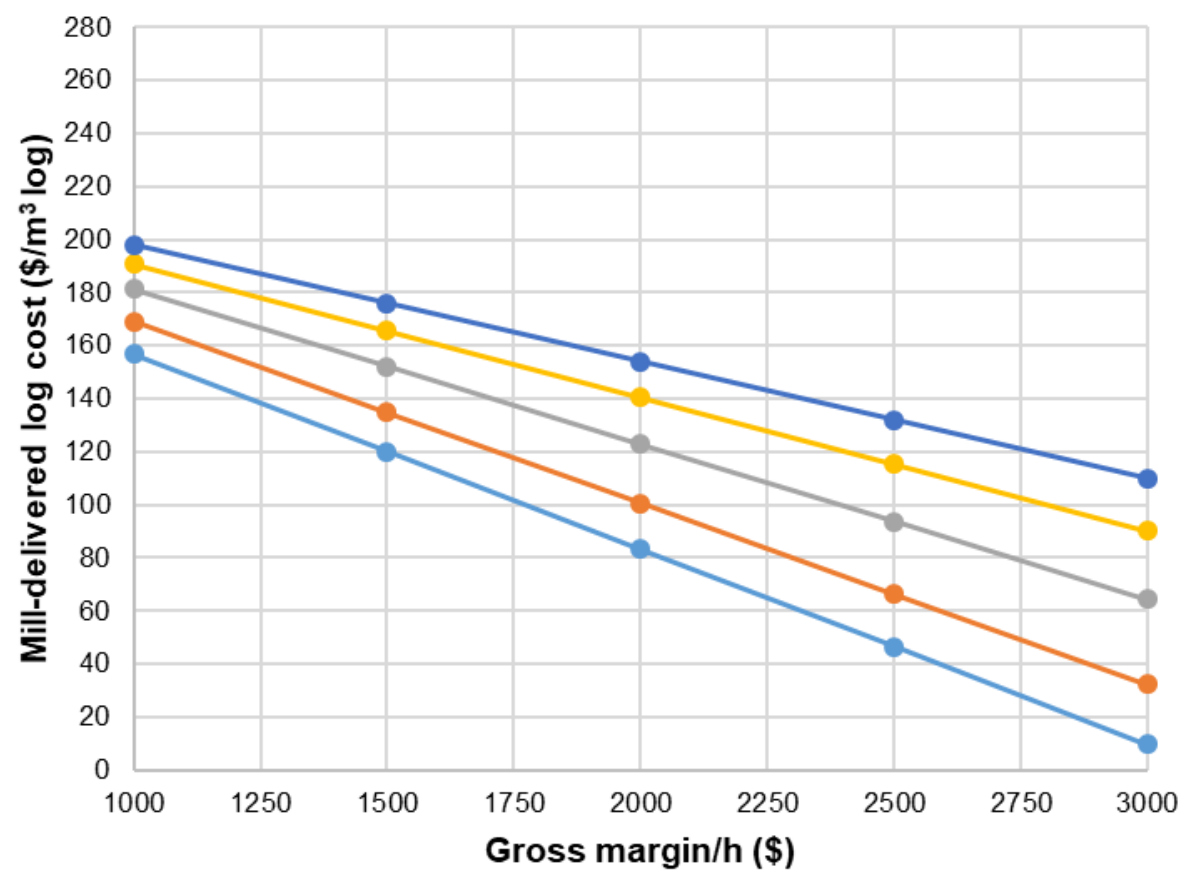

$\longrightarrow$ SEDUB $20 \mathrm{~cm} \longrightarrow$ SEDUB $30 \mathrm{~cm} \longrightarrow$ SEDUB $40 \mathrm{~cm}$

$\multimap$ SEDUB $50 \mathrm{~cm} \longrightarrow$ SEDUB $60 \mathrm{~cm}$

(b) 

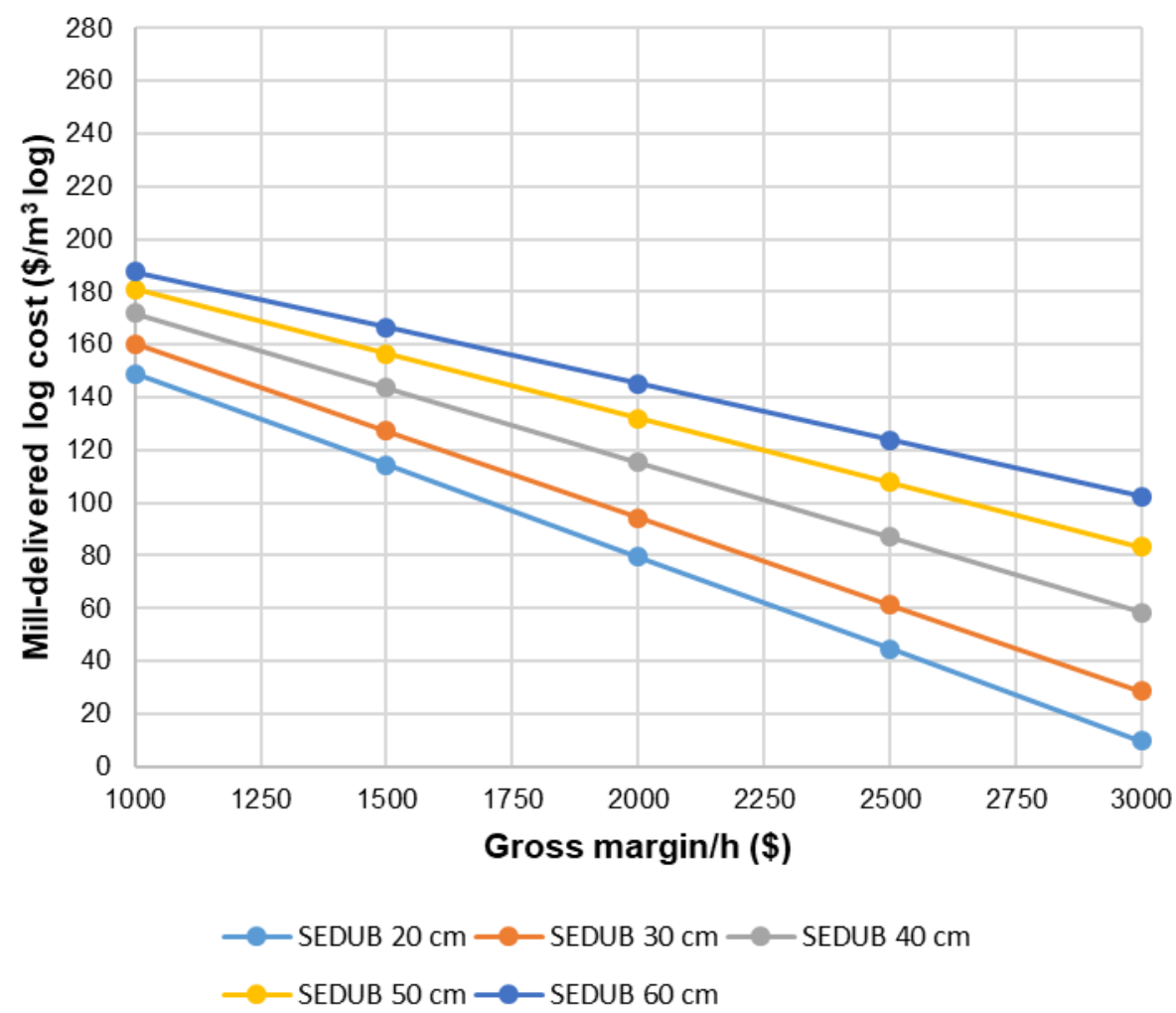

(c)
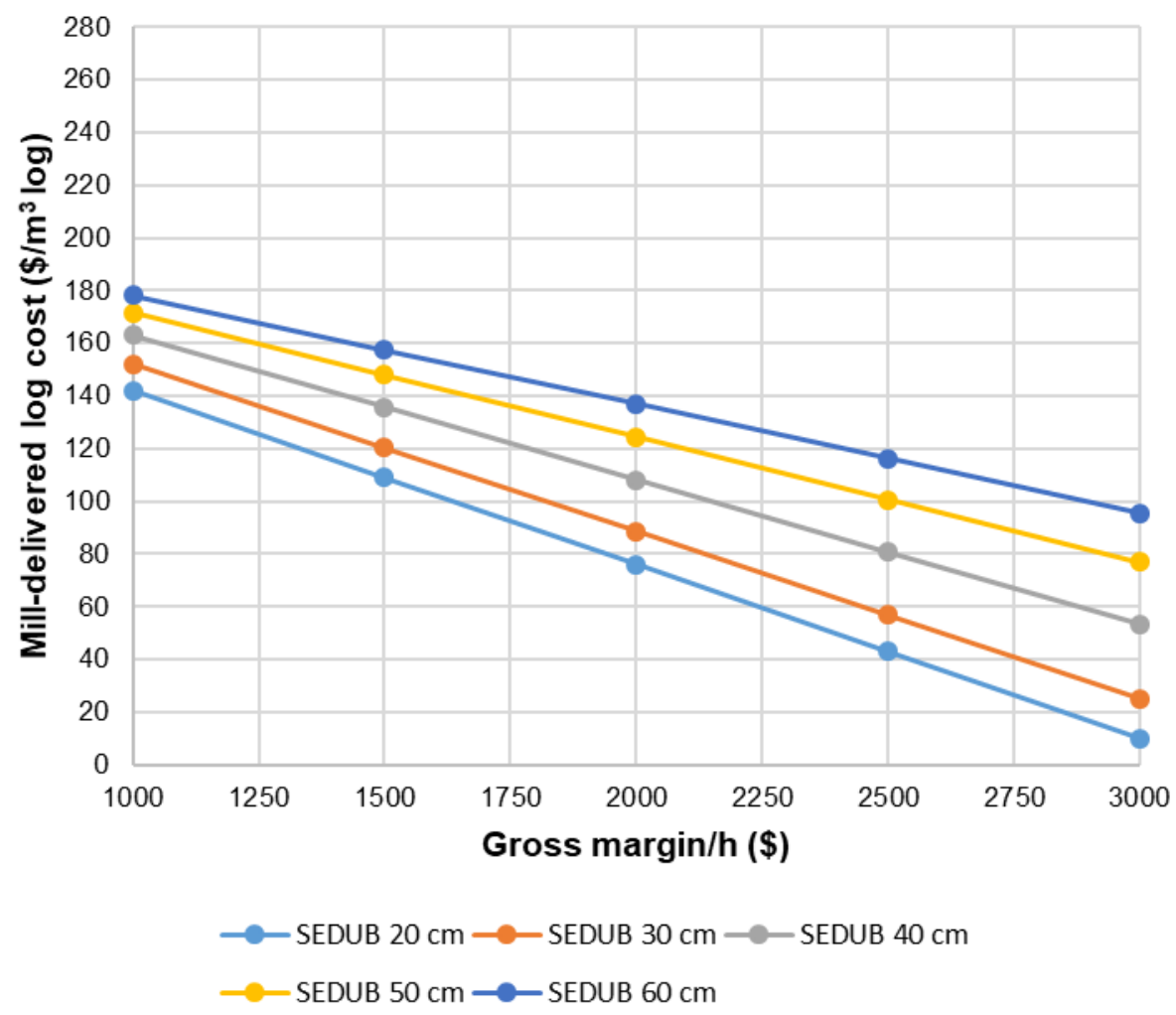

(d) 


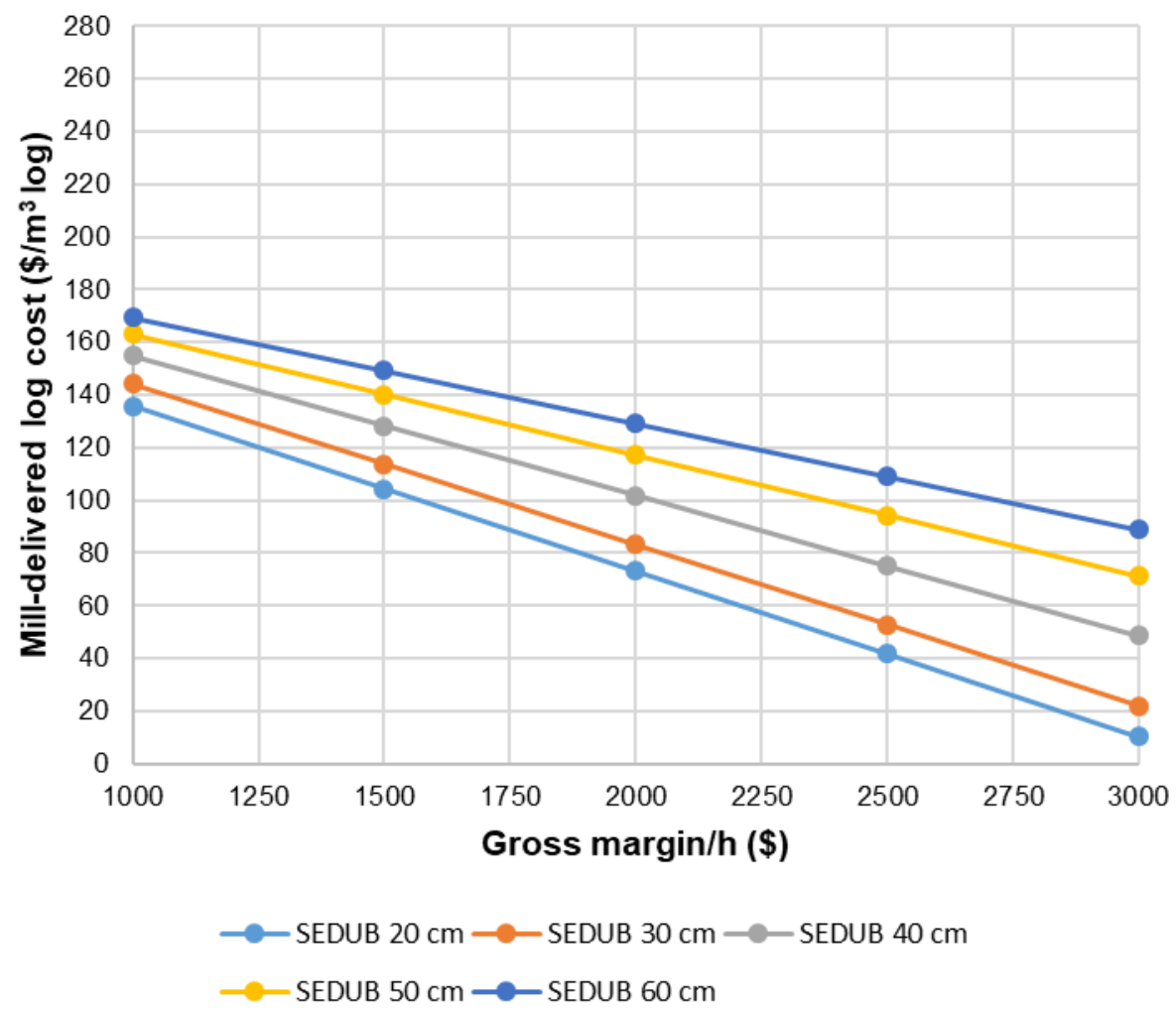

(e)

Fig. 8. Impact of ovality on maximum mill-delivered log cost to achieve particular gross margins $/ \mathrm{h}$; Notes: (a) cylindrical log, (b) $5 \%$ ovality, (c) $10 \%$ ovality, (d) $15 \%$ ovality, and (e) $20 \%$ ovality

This paper systematically examined the effect of log dimensions and geometry on the value of logs for spindleless lathe rotary veneer production. This was achieved by computing the maximum that could be paid for mill-delivered logs while earning a particular target gross margin.

The $\mathrm{MDLC}_{\max }$ was positively related to SEDUB, because net recovery of marketable veneer from log volume increased with SEDUB and the volume of veneer that can be processed per unit of time increased with SEDUB. The MDLC $\mathrm{max}_{\max }$ was negatively related to taper, sweep, and ovality, because NR decreased with these log characteristics. The SEDUB, taper, sweep, and ovality of logs substantially affected the value of veneer that could be produced, and therefore should factor into log procurement decisions. A comparison of the relative importance of alternative log geometry characteristics on MDLC $_{\max }$ was somewhat subjective. However, given the ranges of the attributes considered in this study, log dimension and geometry characteristics could be arranged in decreasing order of impact on $\mathrm{MDLC}_{\max }$ as follows:
1. Sweep
2. SEDUB
3. Taper
4. Ovality

The authors are not aware of other studies that have systematically estimated the effect of taper, sweep, and ovality on the financial performance of veneer manufacture. However, the finding in this study that SEDUB can have a large impact on MDLC $_{\max }$ is 
supported by Kewilaa (2007) and Dobner, Jr et al. (2013), who found that SEDUB explained $74 \%$ and $48 \%$ of the observed recovery of veneer from log volume for their log samples, respectively.

Extensive sensitivity analyses were performed to assess the effect of important parameters on $\mathrm{MDLC}_{\max }$, including the lathe utilisation rate, NR, veneer market price, and veneer recovery by grade. Each of these parameters substantially affected $M D L C_{\max }$. Therefore, context-specific research should be performed to determine appropriate levels for these parameters before applying the methods presented in this paper to support log procurement decisions for a particular spindleless lathe operation.

Estimates of NR in this study were comparable with empirical studies with Eucalyptus and Corymbia species in Australia (Table 1) and with international veneering studies. For example, Belleville et al. (2018) found that dry veneer recovery from small eucalypt logs in Laos averaged between $52 \%$ and $63 \%$. The mean levels of taper, sweep, and ovality in Belleville et al. (2018) were similar to the lowest non-zero levels assessed in the present study. In a Brazilian rotary veneering study of 30-year old Pinus taeda logs that were mostly in the range of $20 \mathrm{~cm}$ to $50 \mathrm{~cm}$ small-end diameter, the average recovery of graded veneer was 54\%. Wang and Dai (2008) reported dry veneer recovery of $47.7 \%$ in the United States from mountain pine beetle-attacked Pinus contorta logs with a mean diameter of $29.5 \mathrm{~cm}$ and when peeled to a core of $9.5-\mathrm{cm}$ diameter. Average veneer recovery from large $(50 \mathrm{~cm}$ to $89 \mathrm{~cm}$ ) native hardwood logs in Indonesia was $60 \%$ (Kewilaa 2007). Higher recoveries of veneer could be achieved with short log lengths because volume loss due to taper and sweep could be minimised. For example, Khoo et al. (2018) found that dry veneer recoveries of $62 \%$ to $65 \%$ of log volume could be achieved with 1.2$\mathrm{m}$ rubber tree logs that ranged in diameter from $15 \mathrm{~cm}$ to $18 \mathrm{~cm}$.

The mean veneer price adopted in this study of $\$ 426 / \mathrm{m}^{3}$ was comparable with market prices of veneer reported in other studies. For example, eucalypt veneer in China reportedly had a market value between about US $\$ 290 / \mathrm{m}^{3}$ to US $\$ 385 / \mathrm{m}^{3}$ (Arnold et al. 2013), and Pinus taeda veneer in Brazil had a market value between US $\$ 48 / \mathrm{m}^{3}$ and US $\$ 314 / \mathrm{m}^{3}$ (Dobner, Jr et al. 2013).

The utility of the $\log$ cost metric adopted in this study, $\mathrm{MDLC}_{\max }$, was in the practical application to guide log procurement decisions, and this is now demonstrated. Suppose the business model of a particular veneer manufacturer demands that gross margins of at least $\$ 1000 / \mathrm{h}$ are earned to cover all non-log fixed and variable costs, including the desired profit margin. The utilisation rate of the lathe is 50\%. From Fig. 6 to Fig. 8, a gross margin of $\$ 2000 / \mathrm{h}$ for a utilisation rate of $100 \%$ is interpreted as $\$ 1000 / \mathrm{h}$ with a 50\% utilisation rate. Table 3 represents the $\log$ market faced by the firm. Milldelivered log costs would be affected by log quality characteristics and haul distance to the mill. However, $\log$ costs varied only by SEDUB in this example for simplicity.

In Australia and internationally, mill-delivered log costs typically rise with log diameter (and quality) (James 2001; Midgley et al. 2007; Arnold et al. 2013; Dobner, Jr et al. 2013; Jay and Dillon 2016). Therefore, veneer manufacturers face a trade-off between higher mill-delivered log cost and higher gross margins per unit of processing time for large diameter logs, and lower mill-delivered log cost and lower gross margins per unit time for small diameter logs. Consequently, as revealed in a study of veneer production from Pinus taeda logs in Brazil, larger logs may not provide the best returns to veneer production (Dobner, Jr et al. 2013).

Venn et al. (2020). "Log geometry for log procurement," BioResources 15(2), 2385-2411. 2406 
Table 3. Hypothetical Log Market Faced by a Veneer Manufacturer and Optimal Log Purchases

\begin{tabular}{|c|c|c|c|c|c|c|c|c|c|c|c|c|c|c|c|c|}
\hline \multirow{3}{*}{$\begin{array}{c}\text { SEDUB } \\
\text { (cm) }\end{array}$} & \multirow{3}{*}{$\begin{array}{c}\text { Log } \\
\text { Cost } \\
\left(\$ / m^{3}\right)^{1}\end{array}$} & \multicolumn{15}{|c|}{ Financially Viable Log Purchases by Log Geometry } \\
\hline & & \multirow{2}{*}{$\begin{array}{c}\text { Cylindrical } \\
\text { Logs }^{2}\end{array}$} & \multicolumn{5}{|c|}{ Taper $(\mathrm{mm} / \mathrm{m})$} & \multicolumn{5}{|c|}{ Sweep $(\mathrm{mm} / \mathrm{m})$} & \multicolumn{4}{|c|}{ Ovality (\%) } \\
\hline & & & 5 & 10 & 20 & 40 & 80 & 5 & 10 & 20 & 40 & 80 & 5 & 10 & 15 & 20 \\
\hline 20 & 80 & & & & & & & & & & & & & & & \\
\hline 30 & 100 & & & & & & & & & & & & & & & \\
\hline 40 & 120 & & & & & & & & & & & & & & & \\
\hline 50 & 150 & & & & & & & & & & & & & & & \\
\hline 60 & 180 & & & & & & & & & & & & & & & \\
\hline
\end{tabular}

In Figs. 6 to 8, the appropriate gross margin/h is located on the $\mathrm{x}$-axis, and the MDLC $_{\max }$ can be read from the $\mathrm{y}$-axis where the selected gross margin intersects the downward sloping MDLC $_{\max }$ schedule. If MDLC $_{\max }$ is greater than the log cost in Table 3, then logs with that dimension and geometry are a financially viable purchase for veneer manufacture. The shaded cells in Table 3 indicate financially viable purchases given the $\log$ costs indicated, which were relatively straight $\operatorname{logs}$ in the $20 \mathrm{~cm}$ to $50 \mathrm{~cm}$ SEDUB diameter classes. In this example, insufficient marketable veneer can be produced from 60cm SEDUB logs to justify the mill-delivered log costs of $\$ 180 / \mathrm{m}^{3}$.

A useful future enhancement of the model would be to accommodate the potential for correlation between taper, sweep, and ovality. Further research would also be useful to test the assumption that veneer grade recovery is independent of $\log$ dimensions and geometry, because larger SEDUB logs may yield higher proportions of higher quality veneer. This could be accommodated within the framework presented in this paper with minor changes to Eq. 10 to make MVRPLV a function of SEDUB.

\section{CONCLUSIONS}

1. For spindleless rotary lathe veneering technology peeling $2.6-\mathrm{m} \log$ s to a core diameter of $4.5 \mathrm{~cm}$, this study quantified the increasing rate of marketable veneer production $/ \mathrm{h}$ of operation from larger diameter rounded billets. The effect of $\log$ dimensions and geometry on the recovery of marketable veneer from mill-delivered log volume was also systematically evaluated, which revealed the log characteristics arranged in decreasing order of impact on marketable veneer recovery were sweep, SEDUB, taper, and ovality. These processing efficiency and recovery of marketable veneer relationships were integrated within a metric that can determine the maximum that can be paid for a $\log$ of a particular log dimension and geometry $\left(\mathrm{MDLC}_{\max }\right)$ while achieving a target gross margin/h of veneer manufacture. This metric is useful for supporting the log procurement decisions of the industry. 
2. The method was presented with parameter estimates that were relevant for veneer manufacture in Australia. Context-specific research should be performed to determine appropriate levels for parameters before applying the methods elsewhere. The method accounted for the potential correlation between SEDUB and each of taper, sweep, and ovality.

\section{ACKNOWLEDGEMENTS}

The authors are grateful for the expert advice and contributions to research activities provided by Big River Group, Austral Plywoods, Parkside Group, Hurford Wholesale, Engineered Wood Products Association of Australasia, Timber Queensland, HQ Plantations, and Wood Products Victoria. The authors also thank two anonymous reviewers for their valuable support to improve earlier versions of the manuscript.

This work was supported by the Queensland Department of Agriculture and Fisheries and the Forest and Wood Products Australia through projects DNB407-1516, entitled "Increasing the Value of Forest Resources Through the Development of Advanced Engineered Wood Products," and VNC402-1617, entitled "Silvicultural Systems to Optimise Value from Northern Australian Mahogany Plantations”.

\section{REFERENCES CITED}

Amishev, D., and Murphy, G. (2009). "Estimating breakeven prices for Douglas-fir veneer quality logs from stiffness graded stands using acoustic tools," Forest Prod. J. 59(4), 45-52.

Andersson, G., Flisberg, P., Nordström, M., Rönnqvist, M., and Wilhelmsson, L. (2016). "A model approach to include wood properties in log sorting and transportation planning," INFOR 54(3), 282-303. DOI: 10.1080/03155986.2016.1198070

Arnold, R. J., Xie, Y. J., Midgley, S. J., Luo, J. Z., and Chen, X. F. (2013). "Emergence and rise of eucalypt veneer production in China," Int. For. Rev. 15(1), 33-47. DOI: $10.1505 / 146554813805927200$

AS/NZS 2269.0:2012 (2012). "Plywood-Structural. Part 0: Specifications," Standards Australia, Sydney, Australia, and Standards New Zealand, Wellington, New Zealand.

Blakemore, P., Morrow, A., Ngo, D., Washusen, R., and Harwood, C. (2010a). Plantation-Grown Eucalyptus nitens: Solid Wood Quality and Processing Performance on Linear Sawing Systems with a Range of Commercial and Experimental Drying Schedules (Report No. 200), Cooperative Research Centre, Hobart, Tasmania, Australia.

Blakemore, P., Morrow, A., Washusen, R., Harwood, C., Wood, M., and Ngo, D. (2010b). Evaluation of Thin-Section Quarter-Sawn Boards and Rotary Veneer from Plantation-Grown Eucalyptus nitens (Report No. 202), Cooperative Research Centre, Hobart, Tasmania, Australia.

De Carvalho, A. M., Lahr, F. A. R., and Bortoletto, Jr, G. (2004). "Use of Brazilian eucalyptus to produce LVL panels," Forest Prod. J. 54(11), 61-64.

Dobner, Jr, M., Nutto, L., and Higa, A. R. (2013). "Recovery rate and quality of rotary peeled veneer from 30-year-old Pinus taeda L. logs," Ann. For. Sci. 70(4), 429-437. DOI: $10.1007 / \mathrm{s} 13595-013-0274-\mathrm{z}$ 
Dorries, S. (2019). Personal communication on May 6, 2019 with the Chief Executive Officer of Responsible Wood, Brisbane, Australia.

Fahey, T. D., and Willlts, S. A. (1991). Veneer Recovery of Douglas-fir from the Coast and Cascade Ranges of Oregon and Washington (PNW-RP-439), U.S. Department of Agriculture, Forest Service, Pacific Northwest Research Station, Portland, OR, USA.

Gaunt, D., Penellum, B., and McKenzie, H. M. (2003). "Eucalyptus nitens laminated veneer lumber structural properties," NZ J. For. Sci. 33(1), 114-125.

Gilbert, B. P., Bailleres, H., Fischer, M. F., Zhang, H., and McGavin, R. L. (2017). "Mechanical properties of rotary veneers recovered from early to midrotation subtropical-hardwood plantation logs for veneer-based composite applications," $J$. Mater. Civ. Eng. 29(10), Article ID 04017194. DOI: 10.1061/(ASCE)MT.19435533.0002055

Hamilton, M. G., Blackburn, D. P., McGavin, R. L., Baillères, H., Vega, M., and Potts, B. M. (2015). "Factors affecting log traits and green rotary-peeled veneer recovery from temperate eucalypt plantations," Ann. For. Sci. 72(3), 357-365. DOI: 10.1007/s13595-014-0430-0

Heräjärvi, H., and Arponen, J. (2008). "Log and veneer quality of Finnish and Russian birch in plywood production," in: Proceedings of the International Panel Products Symposium 2008, M. Spear (ed.), Espoo, Finland, pp. 67-76.

James, R. N. (2001). Defining the Product Log Grades Used in Australia, RIRDC, Canberra, Australia.

Jay, A., and Dillon, A. (2016). "Modelling the outcomes of different silvicultural approaches in the private native forests of north-eastern New South Wales," Aust. For. 79(2), 85-95. DOI: 10.1080/00049158.2015.1123392

Kewilaa, B. (2007). "Effects of wood species and log diameter on veneer recovery," Journal of Tropical Wood Science and Technology 5(2), 49-56.

Khoo, P. S., H'ng, P. S., Chin, K. L., Bakar, E. S., Maminski, M., Raja-Ahmad, R.-N., Lee, C. L., Ashikin, S. N., and Saharudin, M.-H. (2018). "Peeling of small diameter rubber log using spindleless lathe technology: Evaluation of veneer properties from outer to inner radial section of log at different veneer thicknesses," Eur. J. Wood Wood Prod. 76(4), 1335-1346. DOI: 10.1007/s00107-018-1300-5

Leggate, W., Palmer, G., McGavin, R. L., and Muneri, A. (2000). "Productivity, sawn recovery and potential rates of return from eucalypt plantations in Queensland," in: The Future of Eucalypts for Wood Products. Proceedings of an IUFRO Conference, Launceston, Tasmania, Australia, pp. 19-24.

Leggate, W., McGavin, R. L., and Bailleres, H. (2017). A Guide to Manufacturing Rotary Veneer and Products from Small Logs (Monograph No. 182), Australian Centre for International Agricultural Research, Canberra, Australia.

Luo, J., Arnold, R., Ren, S., Jiang, Y., Lu, W., Peng, Y., and Xie, Y. (2013). "Veneer grades, recoveries, and values from 5-year-old eucalypt clones," Ann. For. Sci. 70(4), 417-428. DOI: 10.1007/s13595-013-0268-x

McGavin, R. L., Bailleres, H., Fehrmann, J., and Ozarska, B. (2015a). "Stiffness and density analysis of rotary veneer recovered from six species of Australian plantation hardwoods," BioResources 10(4), 6395-6416. DOI: 10.15376/biores.10.4.6395-6416

McGavin, R. L., Bailleres, H., Hamilton, M., Blackburn, D., Vega, M., and Ozarska, B. (2015b). "Variation in rotary veneer recovery from Australian plantation Eucalyptus globulus and Eucalyptus nitens," BioResources 10(1), 313-329. DOI: 10.15376/biores.10.1.313-329 
McGavin, R. L., Bailleres, H., Lane, F., Blackburn, D., Vega, M., and Ozarska, B. (2014a). "Veneer recovery analysis of plantation eucalypt species using spindleless lathe technology," BioResources 9(1), 613-627. DOI: 10.15376/biores.9.1.613-627

McGavin, R. L., Bailleres, H., Lane, F., Fehrmann, J., and Ozarska, B. (2014b). "Veneer grade analysis of early to mid-rotation plantation eucalyptus species in Australia," BioResources 9(4), 6562-6581. DOI: 10.15376/biores.9.4.6562-6581

McGavin, R. L., and Leggate, W. (2019). "Comparison of processing methods for small diameter logs: Sawing versus rotary peeling," BioResources 14(1), 1545-1563. DOI: 10.15376/biores.14.1.1545-1563

Midgley, S., Lal, P., Bhojvaid, P., and Brown, A. (2007). A Strategy for Developing Market Opportunities for Australian Forest Products in India, Salwood Asia Pacific Pty. Ltd., Canberra, Australia.

Pease, D. A. (1993). "Small-log diet agrees with spindleless lathe," Wood Technology 120, 16-18.

Peng, Y., Washusen, R., Xiang, D., Lan, J., Chen, S., and Arnold, R. (2014). "Grade and value variations in Eucalyptus urophylla $\times$ E. grandis veneer due to variations in initial plantation spacings," Aust. For. 77(1), 39-50. DOI: 10.1080/00049158.2013.877415

Rahayu, I., Denaud, L., Marchal, R., and Darmawan, W. (2015). “Ten new poplar cultivars provide laminated veneer lumber for structural application," Ann. For. Sci. 72(6), 705-715. DOI: 10.1007/s13595-014-0422-0

Reserve Bank of Australia (2019). "Exchange rates," Reserve Bank of Australia, (https://www.rba.gov.au/statistics/frequency/exchange-rates.html), Accessed 13 Aug 2019.

Sorenson, J. (1985). "Spindleless lathe enables plywood comeback," Can. Forest Ind. 105(8), 33-34.

Spelter, H., and Sleet, G. (1989). "Potential reductions in plywood manufacturing costs resulting from improved technology," Forest Prod. J. 39(1), 8-15.

Verkasalo, E. (1997). "Evaluating the potential of European white birch (Betula pubescens) for veneer and plywood by timber and wood quality," in: Proceedings of the Second Workshop "Connection Between Silviculture and Wood Quality Through Modelling and Simulation Software”, G. Nepveu (ed.), Berg-en-Dal, Kruger National Park, South Africa, pp. 431-439.

Verkasalo, E., and Heräjärvi, H. (2009). "Potential of European birch species for product development of veneer and plywood - Recovery, grades and mechanical properties and future market requirements," in: Proceedings of ISCHP 09, $2^{\text {nd }}$ International Scientific Conference on Hardwood Processing, F. Rouger and M. Goueffon (eds.), Paris, France, pp. 11-19.

Wang, B. J., and Dai, C. (2013). "Development of structural laminated veneer lumber from stress graded short-rotation hem-fir veneer," Constr. Build. Mater. 47, 902-909. DOI: 10.1016/j.conbuildmat.2013.05.096

Wang, B. J., and Dai, C. (2008). "Impact of mountain pine beetle-attacked lodgepole pine logs on veneer processing," Wood Fiber Sci. 40(3), 397-411.

Washusen, R., Harwood, C., Morrow, A., Northway, R., Valencia, J. C., Volker, P., Wood, M., and Farrell, R. (2009). "Pruned plantation-grown Eucalyptus nitens: Effect of thinning and conventional processing practices on sawn board quality and recovery," NZ J. For. Sci. 39(1), 39-55. 
Washusen, R. (2011). Processing Plantation-Grown Eucalyptus globulus and E. nitens for Solid-Wood Products-Is It Viable? (Report No. 209), Cooperative Research Centre, Hobart, Tasmania, Australia.

Washusen, R., and Harwood, C. (2011). Processing Plantation-Grown Eucalypt Sawlogs: Modelling Costs and Log Prices for Mills Optimised for the Tasmanian Plantation Resource (Report No. 211), Cooperative Research Centre, Hobart, Tasmania, Australia.

Article submitted: November 10, 2019; Peer review completed: January 23, 2020;

Revised version received and accepted: February 3, 2020; Published: February 11, 2020.

DOI: 10.15376/biores.15.2.2385-2411 